\title{
Measuring Strategic Uncertainty in Coordination Games*
}

\author{
By Frank Heinemann, ${ }^{a}$ Rosemarie Nagel,,${ }^{b}$ and Peter Ockenfels ${ }^{\mathrm{c}}$
}

10 December 2004

\begin{abstract}
This paper explores three aspects of strategic uncertainty: its relation to risk, predictability of behavior and subjective beliefs of players. In a laboratory experiment we measure subjects' certainty equivalents for three coordination games and one lottery. Behavior in coordination games is related to risk aversion, experience seeking, and age.

From the distribution of certainty equivalents we estimate probabilities for successful coordination in a wide range of games. For many games, success of coordination is predictable with a reasonable error rate. The best response to observed behavior is close to the global-game solution.

Comparing choices in coordination games with revealed risk aversion, we estimate subjective probabilities for successful coordination. In games with a low coordination requirement, most subjects underestimate the probability of success. In games with a high coordination requirement, most subjects overestimate this probability.

Estimating probabilistic decision models, we show that the quality of predictions can be improved when individual characteristics are taken into account. Subjects' behavior is consistent with probabilistic beliefs about the aggregate outcome, but inconsistent with probabilistic beliefs about individual behavior.
\end{abstract}

JEL classification: C 72, C 91, D 81, D 84

Keywords: belief formation, coordination games, global game, lotteries, risk aversion, strategic uncertainty

\footnotetext{
${ }^{*}$ For valuable comments, we are grateful to Irina Cojuharenco, Werner Güth, Stephen Morris, Christian Schade, Burkhard Schipper, Andreas Schröder, Joachim Weimann, and various seminar participants in Frankfurt, Darmstadt, Barcelona, and Exeter. All errors remain our responsibility. Rosemarie Nagel acknowledges financial support of Spain's Ministry of Education under Grant SEC2002-03403 and thanks the Barcelona Economics Program of CREA for support.

${ }^{a}$ Ludwig-Maximilians-Universität München, Germany, frank.heinemann@1rz.uni-muenchen.de

${ }^{\mathrm{b}}$ Universitat Pompeu Fabra, Barcelona, Spain, rosemarie.nagel@econ.upf.es

${ }^{\mathrm{c}}$ Goethe-Universität Frankfurt am Main, Germany, peter@ockenfels.com
} 


\section{Introduction}

Since Knight (1921) the literature distinguishes two kinds of uncertainty: exogenous uncertainty (or risk) is characterized by the existence of given (not necessarily known) probabilities for all possible states of the world. A lottery is the prototype of a risky situation. More generally, risky situations are games against nature. Endogenous uncertainty arises in situations, where the outcome depends on social interaction. These are situations of participation in a strategic game.

There is a long going discussion in economics whether and how strategic decision making can be modelled as a game against nature. Luce and Raiffa (1957, p.306) suggest assigning subjective probabilities to an adversary's choices in a game, (without being more specific how to model it): "The problem of individual decision making under uncertainty can be considered a one-person game against a neutral nature. Some of these ideas can be applied indirectly to individual decision making (...) where the adversary is not neutral but a true adversary." Manski (2004) gives an overview of methods for eliciting subjective beliefs and analyses whether they achieve the objective to "improve our ability to predict choice behavior" ( $p$. 1365).

Aumann and Dreze (2004) emphasize that measuring subjective probabilities requires staking a prize on the outcome. In strategic games, staking a prize changes the payoff function and thereby the "rules of the game". To solve this problem they posit a preference order on lotteries whose prizes may be either a pure strategy in a strategic game or a certain outcome. If the preference order satisfies the von Neumann-Morgenstern axioms, it implies the existence of two functions that may be interpreted as a utility function on outcomes and a subjective probability distribution on the adversary's strategies.

We develop a similar method and suggest to measure strategic uncertainty by certainty equivalents. We measure the amount of money at which a subject is indifferent between receiving this money and a situation in which the payoff is subject to strategic uncertainty. Combining certainty equivalents of strategic games with the same subjects' certainty equivalents of lotteries relates strategic behavior to risk aversion and allows measuring subjective beliefs. We apply this method to coordination games with multiple equilibria and show that the predictive power of decision models can be increased by accounting for individual differences in risk aversion and other personal characteristics.

Currently, a number of experimental economists develop new methods to relate risk and uncertainty by comparing behavior of the same subjects in lottery-choice tasks and strategic games. Goree, Holt and Palfrey (2002) combine individual decisions for lotteries with the matching pennies game to show that the inclusion of risk aversion in a quantal response equilibrium can explain systematic deviations of subjects' behavior from Nash equilibrium. Lange, List and Price (2004) relate lottery choices with resale auctions to estimate equilibria under risk aversion. Schechter (2004) and Bohnet and Zweckhauser (2003) combine lottery choices with trust games and show that risk averse subjects make lower contributions. Nyarko and Schotter (2002) estimate subjective beliefs about opponents' behaviour in a repeated 
game to study social learning of beliefs. To our knowledge, we are the first to estimate subjective probabilities in situations of strategic uncertainty by relating strategic choices to risk aversion.

Coordination games with strategic complementarities typically have multiple equilibria. Multiplicity of equilibria is associated with strategic uncertainty to which we cannot assign probabilities by pure deductive reasoning. Imagine a situation, where an investment pays off, if and only if a sufficient number of firms invests in the same industry. If nobody invests, then the investment of a single agent fails. Not investing is an equilibrium. If everybody invests, the investment is profitable. Investing is another equilibrium and it is the efficient strategy profile. In this situation, neoclassical theory cannot predict behavior, nor assign probabilities, because both outcomes are consistent with optimizing behavior and rational expectations. Efficiency considerations are relevant for normative statements, but one cannot rely on them having any descriptive power.

Experiments on coordination games, however, show clear patterns of behavior. Van Huyck, Battalio and Beil $(1990,1991)$ show that subjects coordinate rather quickly on an equilibrium that depends on group size, coordination requirement and experience. A high degree of efficiency can be achieved by matching in pairs, but not in situations that require the coordination of all members in a group of seven or more players. Berninghaus and Erhart (1998, 2001) show that disaggregate information and a larger time horizon enhance efficiency. Heinemann, Nagel and Ockenfels (2004) compare coordination games with public and private information and find no significant difference in predictability of aggregate behavior, even though the private information game has a unique equilibrium, while the public information game has multiple equilibria. Subjects coordinate on equilibria that are fairly predictable and vary (depending on the payoff function) from the payoff-dominant to the risk-dominant equilibrium. Public information does enhance efficiency. Comparative statics with respect to parameters of the payoff function follow the risk-dominant equilibrium. Schmidt et al. (2003) use different coordination games, in which they vary either risk dominance or the level of payoff dominance, holding the other constant. They show that changes in risk dominance affect behavior, while changes in the level of payoff dominance do not.

Risk dominance and other theoretical refinement concepts are characterized by assumptions on players' beliefs about other players' behavior. While some concepts are rather ad hoc, risk dominance has an axiomatic justification, laid out in Harsanyi and Selten (1988). Related to this, the theory of global games, developed by Carlsson and van Damme (1993) and advanced by Morris and Shin (2000), assumes that players behave as if they have private information about payoffs. In the limit, when the variance of private information vanishes, the global game is characterized by the belief that the proportion of players, who contribute to a coordination game has a uniform distribution in [0,1]. In binary-action games with two players the global-game solution coincides with risk dominance. In other games both concepts give similar predictions. Risk dominance has a firm axiomatic foundation, the global-game solution is easier to calculate. 
Morris and Shin (2002) propose that strategic uncertainty can be measured in a game, where private beliefs about the payoff function are combined with private values. We follow this suggestion by exploiting subjects' risk aversion. The degree of risk aversion is private information, and it affects the private value (utility) of a monetary payment. Hellwig (2002) explores the theoretic relation between risk aversion and the global-game approach and finds that the global-game solution can be approached by uncertainty about other player's risk aversion.

In our experiment, we compare lottery choices with choices to engage in coordination games. Thereby, we measure risk aversion and attitudes towards strategic uncertainty. Using the multiple-price-list technique introduced by Holt and Laury (2002), the experiment elicits certainty equivalents for a lottery to win 15 Euro with probability $2 / 3$ and thresholds to participate in a coordination game, where a subject gets 15 Euro, provided that a fraction $k$ of the other players joins the coordination game. Observed thresholds may be interpreted as certainty equivalents for the respective coordination game. Thereby, we have comparable measures for both kinds of uncertainty. The experiment combines these games with an extended questionnaire containing Zuckerman's Sensation Seeking Scale V (SSS-V) that psychologists use to characterize personalities. ${ }^{1}$

Naturally, the higher the fraction of players needed for coordination, the more likely players opt out for the safe payoff. For most subjects, the certainty equivalent of the lottery is in between the thresholds for coordination games with $k=1 / 3$ and $k=2 / 3$. These subjects view actions that require one third of the other players to join as less risky than the lottery, which in turn appears less risky than an action that requires $2 / 3$ of the others to join.

Certainty equivalents of coordination games are positively related to certainty equivalents of lotteries and to the "experience seeking" subscale of the Zuckerman test. Subjects, who avoid risk or new experience, do also avoid strategic uncertainty. Our evidence indicates that behavior in coordination games might also be affected by age. Older participants tend to have higher certainty equivalents than younger subjects.

The distribution of certainty equivalents is sensitive to the subject pool. Running the experiment at three places with tractable differences in the composition of subject pools, we find significant differences in behavior. A possible explanation is that homogeneity of a group increases the expected success of coordination. But, even across the three groups, many coordination games with multiple equilibria have a predictable outcome. For one half of the games covered by our experiment, success or failure can be predicted with an error rate below five per cent for all three data sets. The probability that a randomly selected player chooses the uncertain action can be approximated by a logistic distribution.

For most subjects, the best response to observed behavior is close to the global-game solution. Using lottery choices as measures of individual risk aversion, we estimate utility functions and compare expected utilities of various refinement strategies. For most subjects, the globalgame solution calculated under risk neutrality leads to a higher expected utility than any other considered strategy. From this, we conclude that the global-game solution can be

\footnotetext{
${ }^{1}$ For details, see Zuckerman (1994).
} 
recommended to agents who are engaged in a one-shot coordination game with a maximum payoff of about 15 Euro. For higher payoffs, risk aversion is likely to increase, which may result in another strategy being optimal.

Using revealed risk aversion, we estimate subjective probabilities for successful coordination. In games that require $1 / 3$ of the other players to get a reward, most subjects underestimate success probabilities. In games that require $2 / 3$ of the others or all group members, most subjects overestimate success probabilities. Simulations indicate that subjects have probabilistic beliefs about success or failure of coordination rather than beliefs about the behavior of other players.

For a quantitative analysis of how behavior is affected by parameters of the game and by personal characteristics, we develop and compare four probabilistic decision models. Parameters of the models are estimated by maximizing the likelihood of observed choices. Two models treat decisions as a random functions described by logistic distributions. It is shown that including personal characteristics increases the likelihood of observations significantly. The other two models assume that subjects respond to subjective beliefs that depend on parameters of the game and on personal characteristics. Observed behavior is consistent with probabilistic beliefs about success or failure of coordination. Observations are inconsistent with probabilistic beliefs about other subjects' individual actions.

In Section 2, we define the type of coordination games covered by our experiment. Section 3 describes the experimental design. Section 4 presents results and explores predictability of behavior in coordination games. Section 5 analyzes which strategy can be recommended to a participant of a coordination game as a best response to average behavior. In Section 6, we estimate subjective beliefs and compare them to objective probabilities. Section 7 describes and estimates probabilistic decision models and Section 8 concludes.

\section{Coordination Game}

We are interested in the following coordination game: $N$ players simultaneously decide whether to invest an amount $Z$ in a network technology that is installed if the total revenue is at least $Z K$, where $1<K \leq N$. Contribution yields a return greater than $Z$, if and only if at least $K$ players contribute. Games of this structure are also used to model currency and liquidity crises and bubbles.

Players' choices are strategic complements, and the game has two equilibria in pure strategies for any non-negative $Z$ below the value of the network. If everybody else contributes, the best response is to contribute as well and receive the high payoff. If nobody else decides to invest, then it is a best response to stay out and save the costs.

Suppose that contributions are 5 Euro, the return is 15 Euro to each contributor, and the network is installed, if at least 7 out of 10 players contribute. How many contributions may we expect in this situation and how likely is it that the network is installed and positive externalities unfold? 
Suppose, contributions are 12 Euro and all 10 players must contribute. Here, the payoff to coordination is low and the hurdle is high. May we dare to hope for coordination on the efficient equilibrium in such a situation, and which action should we recommend to a player?

Our experiment is designed to answer these questions, by assigning measures of strategic uncertainty and estimating probabilities for efficient outcomes for this kind of coordination games. In addition, we analyze how behavior in coordination games is related to risk aversion and other personal characteristics.

\section{Design of the Experiment}

Sessions were run at a PC pool in the economics department at the University of Frankfurt and in the LEEX at Universitat Pompeu Fabra, Barcelona, from May until July 2003. In Frankfurt we announced the experiment by e-mail to all students with an e-mail account at the department of business and economics and via leaflets and posters at various places in the university. In order to participate, students replied by e-mail. In Barcelona students were notified via posters within the university and signed up on a list at the door of the laboratory. In both places, most of the participants were business and economics undergraduates. The procedure during the sessions was kept the same throughout all sessions at both places, besides the languages (German and Spanish, respectively). All sessions were computerized, using a program done with z-tree (Fischbacher, 1999). Students were seated in a random order at PCs. Instructions (see Appendix A1) were then read aloud and questions were answered in private. Throughout the sessions students were not allowed to communicate and could not see others' screens.

Subjects were randomly assigned to groups of size $N$, where $N$ was 4,7 or 10 in different sessions. There were at least two groups in each session, and subjects did not know who the other members of their group were. Before starting the experiment, subjects had to answer a few questions concerning their understanding of the rules. The experiment started, when all subjects gave the correct answers to these questions. ${ }^{2}$

In the experiment, subjects face 4 bocks of 10 independent decision situations. One block contains lottery choices and 3 blocks contain coordination games. In each situation subjects decide between two options, $\mathrm{A}$ and $\mathrm{B}$. Option A gives a secure payoff that ranges from $€ 1.50$ to $€ 15.00$ in steps of $€ 1.50$ within each block. The payoff for a B-choice is either zero or $€$ 15.00 in each situation. In the lottery setup the payoff for B depends on the result of throwing a die (simulated by the computer): if the result of the die is 1 or 2, the payoff is zero and if the result of the die is $3,4,5$ or 6 , the payoff is $€ 15$. Figure 1 shows a sample screen of the lottery setup.

\footnotetext{
${ }^{2}$ Sample questions are given in Appendix A2.
} 


\section{Sample Screen}

\begin{tabular}{|c|c|c|c|}
\hline Period- & of 1 & & Time remaining[sec]: 237 \\
\hline \multicolumn{4}{|c|}{ Decide between $\mathrm{A}$ or $\mathrm{B}$ for each of the 10 situations } \\
\hline Number of decision situation & Payment for $\mathrm{A}$ : & Your decision: A or $\mathrm{B}$ & \multirow{3}{*}{$\begin{array}{l}\text { Payment for } \mathrm{B} \text { : } \\
\text { - Euro, if the result of the die is } 1 \\
\text { or } 2 \\
15 \text { Euros, if the result of the die is } \\
3,4,5 \text {, or } 6 \text {. }\end{array}$} \\
\hline 1 & 1.50 Euro & A $\subset \subset \mathrm{B}$ & \\
\hline 2 & 3.00 Euro & A $C \subset \mathrm{B}$ & \\
\hline 3 & 4.50 Euro & A $\subset \subset \mathrm{B}$ & dito. \\
\hline 4 & 6.00 Euro & A $C \mathrm{CB}$ & dito. \\
\hline 5 & 7.50 Euro & A $C \subset \mathrm{B}$ & dito. \\
\hline 6 & 9.00 Euro & A $\subset \subset \mathrm{B}$ & dito. \\
\hline 7 & 10.50 Euro & A $\subset \subset \mathrm{B}$ & dito. \\
\hline 8 & 12.00 Euro & A $C \circ \mathrm{B}$ & dito. \\
\hline 9 & 13.50 Euro & A $C \subset \mathrm{B}$ & dito. \\
\hline \multirow[t]{2}{*}{10} & 15.00 Euro & A $C \odot \mathrm{B}$ & \multirow[t]{2}{*}{ dito. } \\
\hline & & & \\
\hline \\
\hline \multicolumn{4}{|c|}{$\begin{array}{l}\text { Help } \\
\text { When you have decided please press the button OK. }\end{array}$} \\
\hline
\end{tabular}

Figure 1. Screen of the lottery setup. "ditto" means that in each situation the payment for B follows the same structure.

Coordination-game choices are as similar as possible: here, the payoff for option B is $€ 15$, provided that at least $K$ out of $N$ members of the subject's group (including her- or himself) chose $\mathrm{B}$ in this situation, and otherwise 0 Euro, where $K$ varied across sessions and setups, but is kept constant throughout the ten situations of a setup. In the coordination-game setup, the last column on the screen shows the text "Payment for B: 0 Euro if less than $K$ members of your group choose B. 15 Euros if at least $K$ members of your group choose B." Parameter $K$ is replaced by the appropriate number.

To avoid hedging, only one out of the 40 situations is selected randomly for payments. In addition, we paid each subject a show-up fee of $€ 5$.

The four setups were given one after another without feedback. After completing all four setups, subjects were informed about the selected situation, on the result of the die (if the selected situation was a lottery choice) or how many members of their group had chosen B in this situation (if the selected situation contained a coordination game), and on their own profit.

Afterwards, each player had to answer a questionnaire asking for personal data, questions concerning the experiment, questions about attitudes towards various kinds of risk, and the Zuckerman Sensation Seeking Scale V (SSS-V). The duration of the experiment was 40 to 60 minutes with an average payoff of $€ 16.68$ per subject.

In each session, we used one particular group size $N$, the same lottery block and three blocks with different coordination requirements $K$. Combinations of $N$ and $K$ were chosen in such a way that each subject was faced with situations that required one third, two third or all of the 
other group members to take the same position in order to be successful with option B. Thus, $k=(K-1) /(N-1)$ equals $1 / 3,2 / 3$ or 1 in the three coordination setups of each session. Table 1 shows the parameter combinations used in the experiment.

\section{Parameters used in the experiment}

\begin{tabular}{llll}
\hline & $k=1 / 3$ & $k=2 / 3$ & $k=1$ \\
\hline$N=4$ & $K=2$ & $K=3$ & $K=4$ \\
$N=7$ & $K=3$ & $K=5$ & $K=7$ \\
$N=10$ & $K=4$ & $K=7$ & $K=10$ \\
\hline
\end{tabular}

Table 1.

As subjects did not receive any feedback until they had completed all forty decisions, the order of the four decision blocks should not matter too much. To minimize systematic order effects on the data, we changed the order between sessions with otherwise equal parameters. Table 2 gives an overview of the sessions and applied parameters. In total we ran 10 computerized sessions with 174 participants. Each session had a different treatment.

Heinemann, Scivos and Stein (2004) have done a hand-run experiment that combines our treatments $4 \mathrm{C}, 7 \mathrm{C}$, or $10 \mathrm{C}$ (with payoffs scaled down by 0.4 ) with some other games but no Zuckerman test. Subjects were 86 participants of a meeting for particular intelligent people ${ }^{3}$ in Köln. We include these data in our presentation.

\section{Overview of sessions}

\begin{tabular}{ccccc}
\hline treatment & $\begin{array}{c}\text { Group size } \\
N\end{array}$ & $\begin{array}{c}\text { Order of blocks } \\
(\mathrm{L}=\text { lottery, numbers }=K)\end{array}$ & location & Number of subjects \\
\hline 4A & 4 & $\mathrm{~L}-4-3-2$ & Frankfurt & 20 \\
4B & 4 & $\mathrm{~L}-2-3-4$ & Frankfurt & 16 \\
4C & 4 & $4-3-2-\mathrm{L}$ & Frankfurt & 12 \\
4D & 4 & $2-3-4-\mathrm{L}$ & Frankfurt & 16 \\
7A & 7 & $\mathrm{~L}-7-5-3$ & Frankfurt & 21 \\
7B & 7 & $\mathrm{~L}-3-5-7$ & Barcelona & 14 \\
7C & 7 & $7-5-3-\mathrm{L}$ & Frankfurt & 21 \\
7D & 7 & $3-5-7-\mathrm{L}$ & Barcelona & 14 \\
10C & 10 & $10-7-4-\mathrm{L}$ & Frankfurt & 20 \\
10D & 10 & $4-7-10-\mathrm{L}$ & Frankfurt & 20 \\
\hline \multicolumn{7}{c}{ Total number of subjects in computerized sessions: } \\
\hline 4C & 4 & $4-3-2-\mathrm{L}$ & Köln & 174 \\
7C & 7 & $7-5-3-\mathrm{L}$ & Köln & 28 \\
10C & 10 & $10-7-4-\mathrm{L}$ & Köln & 30 \\
\hline \multicolumn{5}{c}{ Total number of subjects in hand-run sessions: } \\
\hline
\end{tabular}

Table 2.

\footnotetext{
${ }^{3} 65$ Members of MENSA in Germany and 21 interested visitors.
} 
The chosen design has been motivated by several considerations: we use a one-shot game, because Van Huyck, Battalio and Beil (1991) and Heinemann, Nagel and Ockenfels (2004) have shown that in repeated coordination games the final outcome is often determined by initial behavior. We are interested in explaining the starting points of such a convergence process. We select a single situation for payments to avoid hedging. This gives us the highest possible impact of risk aversion on any decision. Two high-stake sessions in Heinemann, Nagel and Ockenfels (2004) indicate that paying a randomly selected situation does indeed evoke risk-averse behavior in coordination games.

We present the ten situations in each block ordered for the safe payoff, because Heinemann, Nagel and Ockenfels (2004) show in a similar coordination game that a vast majority of subjects plays threshold strategies with at most one switch between actions even when situations are presented in a random order. Presenting options in an ordered fashion strengthens the selection of thresholds and, thereby, increases the number of data sets that can be used for statistical analyzes. This design is called a "multiple-price-list" and has been introduced by Holt and Laury (2002) for measuring risk aversion.

For measuring subjective beliefs, we could also have asked subjects to decide between lotteries and strategic uncertainty directly. But, measuring separate certainty equivalents for both kinds of uncertainty yields identified measures for risk aversion and strategic uncertainty that we use to analyze optimal behavior and to estimate probabilistic decision models.

We did not ask subjects for their beliefs about success or failure of coordination directly. Eliciting beliefs requires an incentive. A direct mechanism asks for beliefs and rewards subjects according to the distance between their guess and the outcome of a game. Point beliefs give less precise measures of strategic uncertainty. Asking for probabilities would have imposed that beliefs are probability distributions, while our design has the possibility of behavior being inconsistent with beliefs in form of probability distributions.

The literature distinguishes between risk aversion and ambiguity aversion. The latter adds to risk aversion in games, where probabilities are not known. Camerer and Karjalainen (1994) conduct a series of experiments to measure ambiguity aversion in strategic games by subadditivity of subjective beliefs. They find only small degrees of subadditivity. Furthermore, in most games the effects of ambiguity aversion are very similar to risk aversion. In our experiment, subadditivity cannot be tested, ambiguity aversion is not identified. When we measure subjective probabilities for successful coordination in Sections 5 and 6, they may be viewed at as a compound of additive probabilities and a factor smaller than one that accounts for uncertainty aversion. However, it is not possible to separate both effects without complicating the design to such an extent that our main objectives would have been endangered. 


\section{Results}

\subsection{Individual Choices}

Lottery and coordination-game setups are framed as similar as possible: within a setup, subjects decide between an option A with increasing safe payoffs and an option B with a risky or uncertain payoff. In all setups, subjects typically choose B when the alternative safe payoff is low and opt for A when the safe payoff is high, with only one switch. Thereby, we have approximate measures of certainty equivalents for the lottery up to an interval of $€ 1.50$ and comparable thresholds for coordination games that may be interpreted as certainty equivalents for the coordination games. Data are displayed in Appendix B.

\section{Result 1: About 90 per cent of all subjects use threshold strategies.}

We call a subject's behavior "threshold strategy", if the subject never switches from A to B for rising safe payoffs. In Frankfurt, 131 out of 146 subjects use threshold strategies in all four setups (including those, who chose the same action in all ten situations of a setup). In Barcelona, threshold strategies were chosen by 27 out of 28 subjects. In Köln threshold strategies were used by 85 out of the 86 subjects. The widespread use of threshold strategies is in line with previous experiments that presented situations without the alternatives being ordered. $^{4}$

Some subjects (7 in Frankfurt, 4 in Barcelona, and 1 in Köln) chose the lottery in all ten situations, even when the alternative safe payoff was 15 . This is inconsistent with utility maximization. Three subjects in Frankfurt and one in Barcelona did not qomplete the Zuckerman test. Two subjects in Köln failed to state their age gender. Some statistical analyses will only consider data from subjects, who used threshold strategies in all four setups, completed the relevant part of the questionnaire, and chose a safe payoff of 15 , when the alternative was a lottery yielding 15 with probability $2 / 3$. These are 121 subjects in Frankfurt, 22 in Barcelona, and 84 in Köln.

Table 3 gives a summary statistic of the number of B-choices by these subjects. Note that for a threshold strategy, the highest safe payment, at which B is chosen, equals the number of Bchoices times $€ 1.50$.

\footnotetext{
${ }^{4}$ For details, see Heinemann, Nagel and Ockenfels (2004).
} 
Average number of B-choices (standard deviation)

\begin{tabular}{lccccc}
\hline $\begin{array}{l}\text { Group size } \\
\text { Location }\end{array}$ & $\begin{array}{c}\text { Number of } \\
\text { subjects }\end{array}$ & Lottery & \multicolumn{3}{c}{ Coordination games } \\
\hline$N=4$ & 56 & $\mathbf{5 . 0 4}$ & $\mathbf{6 . 1 8}$ & $\mathbf{4 . 4 1}$ & 3.25 \\
Frankfurt & & $(1.73)$ & $(2.01)$ & $(2.16)$ & $(2.57)$ \\
$N=7$ & 35 & $\mathbf{4 . 9 7}$ & $\mathbf{5 . 7 4}$ & $\mathbf{4 . 1 1}$ & $\mathbf{2 . 9 1}$ \\
Frankfurt & & $(1.95)$ & $(2.41)$ & $(2.18)$ & $(2.17)$ \\
$N=10$ & 33 & $\mathbf{5 . 0 3}$ & $\mathbf{6 . 2 4}$ & $\mathbf{4 . 3 6}$ & $\mathbf{2 . 6 7}$ \\
Frankfurt & & $(1.76)$ & $(2.26)$ & $(2.50)$ & $(2.57)$ \\
\hline$N=7$ & 23 & $\mathbf{6 , 0 9}$ & $\mathbf{7 , 3 9}$ & $\mathbf{6 , 6 1}$ & 5,78 \\
Barcelona & & $(2,09)$ & $(2,57)$ & $(2,93)$ & $(3,67)$ \\
\hline$N=4$ & 27 & $\mathbf{5 . 4 1}$ & $\mathbf{7 . 6 3}$ & $\mathbf{5 . 5 2}$ & 3.81 \\
Köln & & $(1.25)$ & $(1.64)$ & $(2.29)$ & $(2.82)$ \\
$N=7$ & 28 & $\mathbf{5 . 6 4}$ & $\mathbf{8 . 0 4}$ & $\mathbf{6 . 5 0}$ & $\mathbf{5 . 0 4}$ \\
Köln & & $(2.23)$ & $(1.62)$ & $(2.62)$ & $(3.35)$ \\
$N=10$ & 29 & $\mathbf{5 . 6 6}$ & $\mathbf{7 . 3 1}$ & $\mathbf{5 . 6 2}$ & 3.93 \\
Köln & & $(1.47)$ & $(1.97)$ & $(2.13)$ & $(2.46)$ \\
\hline Table 3. Data
\end{tabular}

Table 3. Data from subjects with threshold strategies and less than 10 B-choices in the lottery setup.

Table 4 presents results from linear regressions with the number of B-choices in coordination setups as explained variable. Here, we also use age and gender and the four subscales of Zuckerman's SSS-V as explaining variables. Since each subject selects a threshold for three coordination games, a simple OLS-regression overestimates significance levels. We correct this by using a clustered OLS-regression with clusters being defined by subjects. The session in Köln did not include the Zuckerman Test. We present results for different subject pools separately. Some of the further analyses consider only data from Frankfurt and Köln, because the sample from Barcelona is too small. 


\begin{tabular}{|c|c|c|c|c|}
\hline \multirow[b]{2}{*}{ Explaining Variables } & \multicolumn{4}{|c|}{ Coefficients ( $\mathrm{t}$-values) of regression with data from } \\
\hline & Frankfurt & Barcelona & Köln & all locations \\
\hline constant & $\begin{array}{c}2.79 \\
(1.68)\end{array}$ & $\begin{array}{l}1.73 \\
(0.27)\end{array}$ & $\begin{array}{l}5.38 * * * \\
(4.50)\end{array}$ & $\begin{array}{c}0.60 \\
(0.75)\end{array}$ \\
\hline Dummy: $1=$ Barcelona & & & & $\begin{array}{l}1.85 * * * \\
(3.29)\end{array}$ \\
\hline Dummy: 1=Köln & & & & $\begin{array}{l}0.99 * * * \\
(3.59)\end{array}$ \\
\hline Group size $N$ & $\begin{array}{l}-0.06 \\
(-0.68)\end{array}$ & & $\begin{array}{l}-0.07 \\
(-0.81)\end{array}$ & $\begin{array}{l}-0.06 \\
(-1.26)\end{array}$ \\
\hline $\begin{array}{l}\text { Coordination } \\
\text { requirement } k\end{array}$ & $\begin{array}{l}-4.56 * * * \\
(-14.04)\end{array}$ & $\begin{array}{l}-2.52 * * * \\
(-3.44)\end{array}$ & $\begin{array}{l}-5.05 * * * \\
(-12.76)\end{array}$ & $\begin{array}{l}-0.93 * * \\
(-2.44)\end{array}$ \\
\hline $\begin{array}{l}\text { Number of B-choices } \\
\text { in lottery }\end{array}$ & $\begin{array}{l}0.55 * * * \\
(5.94)\end{array}$ & $\begin{array}{l}1.18 * * * \\
(5.03)\end{array}$ & $\begin{array}{l}0.38 * * * \\
(2.65)\end{array}$ & $\begin{array}{l}0.57 * * * \\
(7.07)\end{array}$ \\
\hline Age & $\begin{array}{c}0.04 \\
(0.77)\end{array}$ & $\begin{array}{c}0.11 \\
(0.45)\end{array}$ & $\begin{array}{l}0.07 * * \\
(2.62)\end{array}$ & $\begin{array}{l}0.07 * * * \\
(2.87)\end{array}$ \\
\hline $\begin{array}{l}\text { Gender }(0=\text { female, } \\
1=\text { male })\end{array}$ & $\begin{array}{c}0.57 \\
(1.56)\end{array}$ & $\begin{array}{c}0.52 \\
(0.40)\end{array}$ & $\begin{array}{c}0.37 \\
(0.90)\end{array}$ & $\begin{array}{c}0.40 \\
(1.58)\end{array}$ \\
\hline $\begin{array}{l}\text { Boredom } \\
\text { suspectability (BS) }\end{array}$ & $\begin{array}{l}-0.09 \\
(-1.28)\end{array}$ & $\begin{array}{c}-0.70 \\
(-1.29)\end{array}$ & & \\
\hline Disinhibition (DIS) & $\begin{array}{l}-0.05 \\
(-0.64)\end{array}$ & $\begin{array}{c}0.36 \\
(1.54)\end{array}$ & & \\
\hline $\begin{array}{l}\text { Experience seeking } \\
\text { (ES) }\end{array}$ & $\begin{array}{l}0.23 * * * \\
(2.83)\end{array}$ & $\begin{array}{l}-0.11 \\
(-0.43)\end{array}$ & & \\
\hline $\begin{array}{l}\text { Thrill and adventure } \\
\text { seeking (TAS) }\end{array}$ & $\begin{array}{c}0.04 \\
(0.59)\end{array}$ & $\begin{array}{l}-0.25 \\
(-0.98)\end{array}$ & & \\
\hline $\mathrm{R}^{2}$ (adjusted $\left.\mathrm{R}^{2}\right)$ & $0,44(0,43)$ & $0.50(0.44)$ & $0.35(0.34)$ & $0.24(0.24)$ \\
\hline Number of subjects & 121 & 22 & 82 & 229 \\
\hline
\end{tabular}

Table 4. Significance levels: * 5\%, ** 2.5\%, *** 1\%.

The following results summarize the insights from Table 3 and 4.

\section{Result 2: The number of B-choices decreases with increasing coordination requirement $k$.}

The number of B-choices in coordination games is significantly affected by the coordination requirement $k$, because most subjects lower their threshold when $k$ increases (see Table 5 below). 


\section{Result 3: In coordination games the dispersion of thresholds (standard deviation) is higher than in lottery setups. It tends to increase in $k$.}

Table 3 shows (with one exception: Köln, $N=7, k=1 / 3$ ) that the standard deviation of thresholds in coordination games are higher than in lottery setups. In lottery setups, different thresholds are an expression of different degrees of risk aversion. In coordination games, there is an additional source of diversity: subjective beliefs about successful coordination. With rising coordination requirement $k$ the standard deviation of thresholds increases (with one exception: Frankfurt, $N=7$ ). This indicates that subjective beliefs are more diverse when coordination becomes more difficult.

\section{Result 4: Group size $N$ has no significant effect on the number of B-choices.}

We have chosen parameters such that for each subject success with B requires certain fractions of other group members to take the same action. This has the effect that subjects do not respond to $N$, when $k$ is held constant. If, instead $K$ is held constant, $N$ has a strong effect, because then $N$ determines the relative hurdle to coordination. To see this, compare the average number of B-choices in situations with the same $K$ but different $N$ : situations with ( $N$ $=4, k=2 / 3)$ and those with $(N=7, k=1 / 3)$, both have $K=3$. Similarly $(N=4, k=1)$ and $(N$ $=10, k=1 / 3)$ have $K=4$, and $(N=7, k=1)$ and $(N=10, k=2 / 3)$ have $K=7$. In these pairs of situations a larger group size eases coordination and leads to a higher number of B-choices. While behaviour does not respond to $N$ for constant $k$, the group size $N$ has a negative impact on the objective probability of success, as will be shown in Table 6, below. Apparently, subjects do not expect this effect.

\section{Result 5: There are significant differences between subject pools.}

In Barcelona and Köln thresholds are significantly higher than in Frankfurt. The session in Köln is not entirely comparable though, because it was done in paper form and combined our treatments with four other types of games. But, there are differences in the subject pool as well. 76 per cent of the participants in Köln are members of MENSA. Membership requires an IQ above 130. Some knew each other from previous meetings. With respect to profession and age, subjects in Köln are more diverse than student populations. With respect to origin and nationality, student population in Frankfurt is more diverse than subject pools in Köln and Barcelona. Students in Barcelona have more experience with experiments.

Sessions in Barcelona and Köln do also show higher numbers of B-choices in the lottery setup than sessions in Frankfurt. This indicates that risk aversion differs among these groups. For the session in Köln, lower risk aversion can be explained by the down-scaled payoff and combination with other games that also contributed to subjects' earnings. In Barcelona, most subjects behave as risk lovers. This may be an effect of the small sample. ${ }^{5}$ Because of these

\footnotetext{
${ }^{5}$ In Barcelona, one of the two sessions had 10 out of 14 subjects choosing the lottery, when the alternative safe payoff was higher than the expected value of the lottery. Three subjects chose B in all situations of the
} 
differences, we present results for different subject pools separately throughout this paper and use the different groups for out-of-sample tests.

Result 6: The number of B-choices in coordination games is positively related to the number of B-choices in the lottery setup.

The number of B-choices in the lottery setup is a measure of risk aversion. The higher this number, the lower is a subject's revealed risk aversion. Regression results indicate that risk averse subjects choose B less often in coordination games. It is highly significant in all three samples. This observation has an important consequence: assume that subjective beliefs and risk aversion are distributed independently. If subjects have probabilistic beliefs about others' strategies, those with higher risk aversion should, on average, have lower certainty equivalents for coordination games. Otherwise, we could reject the hypothesis that beliefs are probabilities that are independently distributed from risk aversion. Result 6 supports this hypothesis and tells us that subjects behave as if they have probabilistic beliefs about the outcome of coordination games. This justifies the common approach to model beliefs as probability distributions, even when there is no exogenous random process.

\section{Result 7: The number of B-choices in coordination games is positively related to the experience seeking subscale of the Zuckerman test.}

Combined, Results 6 and 7 tell us, that subjects, who avoid risk or new experience, tend to avoid strategic uncertainty. In Barcelona, experience seeking has no significant impact. We attribute this to the small sample.

Result 8: The number of B-choices in coordination games tends to be higher for older participants. Gender has no significant impact.

There is little age variation among subjects in Frankfurt and Barcelona. Participants of the MENSA meeting in Köln are more diverse in respect of age (16 to 51). Here, age is significant. Older subjects opt more often for coordination. ${ }^{6}$ Males tend to choose the uncertain action more frequently than females, but $\mathrm{p}$-values are above $10 \%$.

Thresholds tell us, how risky a subject views a situation to be. The lower the certainty equivalent of a game is, the more risk seems to be associated with it. This allows ranking and comparing situations of strategic uncertainty with situations of exogenously given probabilities. Table 5 shows how subjects in Frankfurt changed their thresholds between the four decision blocks.

experiment. This session may be an outlier. We could not find any control-mistakes, and we do not want to "clean" the sample. Therefore, we keep these data in.

${ }^{6}$ We did not ask subjects to state their personal income that may be related to age among the subjects in Köln. 
Pair wise comparison of thresholds

\begin{tabular}{lcccccc}
\hline $\begin{array}{l}\text { Percentage } \\
\text { of subjects, } \\
\text { who choose }\end{array}$ & $\begin{array}{c}\text { in games } \\
\text { with } k=1 / 3 \\
\text { than in } \\
\text { lottery }\end{array}$ & $\begin{array}{c}\text { in games } \\
\text { with } k=2 / 3 \\
\text { than in } \\
\text { lottery }\end{array}$ & $\begin{array}{c}\text { in games } \\
\text { with } k=1 \\
\text { than in } \\
\text { lottery }\end{array}$ & $\begin{array}{c}\text { in games } \\
\text { with } k=2 / 3 \\
\text { than for } \\
k=1 / 3\end{array}$ & $\begin{array}{c}\text { in games } \\
\text { with } k=1 \\
\text { than for } \\
k=2 / 3\end{array}$ & $\begin{array}{c}\text { in games } \\
\text { with } k=1 \\
\text { than for } \\
k=1 / 3\end{array}$ \\
\hline $\begin{array}{l}\text { a lower } \\
\text { threshold }\end{array}$ & $15 \%$ & $52 \%$ & $76 \%$ & $80 \%$ & $72 \%$ & $88 \%$ \\
$\begin{array}{l}\text { the same } \\
\text { threshold }\end{array}$ & $30 \%$ & $31 \%$ & $12 \%$ & $18 \%$ & $25 \%$ & $9 \%$ \\
$\begin{array}{l}\text { a higher } \\
\text { threshold }\end{array}$ & $55 \%$ & $18 \%$ & $11 \%$ & $2 \%$ & $3 \%$ & $3 \%$ \\
\hline
\end{tabular}

Table 5. Data from subjects with threshold strategies in Frankfurt.

\section{Result 9: Most subjects have higher certainty equivalents for a coordination game with $k=1 / 3$ than for a lottery with a winning probability of $2 / 3$, while they have lower certainty equivalents for a game with $k=1$.}

For $k=1 / 3$, a majority of $55 \%$ chose a higher threshold than in the lottery. They view this coordination game as less risky than the lottery. Only $15 \%$ reveal an opposite view. In the coordination game with $k=2 / 3$, the proportions are turned around: more than half of all subjects view the coordination game with $k=2 / 3$ as more risky than the lottery, while $18 \%$ have the opposite view. $76 \%$ view the coordination game with $k=1$ as more risky than the lottery, but still 11\% take the other side.

Subjects in Barcelona and Köln seemed to have different perceptions of strategic uncertainty. In these locations, the median subjects chose the same threshold in the coordination game with $k=2 / 3$ and in the lottery. The common feature of behavior in all three subject pools is that most subjects view a coordination game with $k=1 / 3$ as less risky than the lottery, while a game with $k=1$ is viewed as riskier than this lottery.

The right three columns of Table 5 show that a vast majority of all subjects lowered their thresholds with increasing in $k$. In only $2 \%$ thresholds are increasing in $k$. Thus, subjects view a situation as more risky, when the coordination requirement rises. This further explains Result 2. In Barcelona this effect is lower, because half of the subjects did not change their threshold in response to an increase in $k$.

\subsection{Aggregate Outcomes}

Next, we analyze the distribution of individual thresholds and its implications for the probability of successful coordination in the various coordination games. The experiment covers a range of 90 binary-choice games, distinguished by group size, payoff for A, and hurdle to coordination on B. For each of these games, we have data from more than 60 subjects, at least 23 in one location. The proportion of subjects playing B serves as a measure for the probability that a randomly drawn subject chooses B. This allows calculating the probability of successful coordination for each game. 
Figures 2 and 3 show the proportion of subjects, who chose B conditional on the alternative safe payoff, denoted by X. Figure 2 rests on data from all subjects in Frankfurt who played threshold strategies. Figure 3 rests on threshold players in Köln. Aggregate behavior of subjects, who did not play threshold strategies in all four setups, cannot be distinguished from random behavior.

The proportion of B-choices can be estimated with a logistic distribution. As a first step to an empirical theory of coordination, we suggest to describe the probability that a person chooses $\mathrm{B}$, when the alternative is a safe payoff of $X$ Euro and success of B requires a fraction $k$ of other people to yield a payoff of 15 Euro, by a logistic function

$$
p=\frac{1}{1+\exp (a-b X-c k)} \text {. }
$$

Table 7 presents parameter estimates based on the decisions of threshold-players in all three locations. Estimated probabilities $\hat{p}$ are presented as curves in Figures 2 and 3 to display the data fit. The obtained fit is high and the estimates allow out of sample tests. We can reject the parameters estimated in Frankfurt by the data from Köln and vice versa.

\section{Estimated logit model}

\begin{tabular}{lccc}
\hline & $\hat{a}$ & $\hat{b}$ & $\hat{c}$ \\
Estimates from Frankfurt data & -5.69 & -0.45 & -3.55 \\
Estimates from Barcelona data & -4.13 & -0.27 & -1.26 \\
Estimates from Köln data & -6.81 & -0.44 & -3.78 \\
\hline
\end{tabular}

Table 7. 


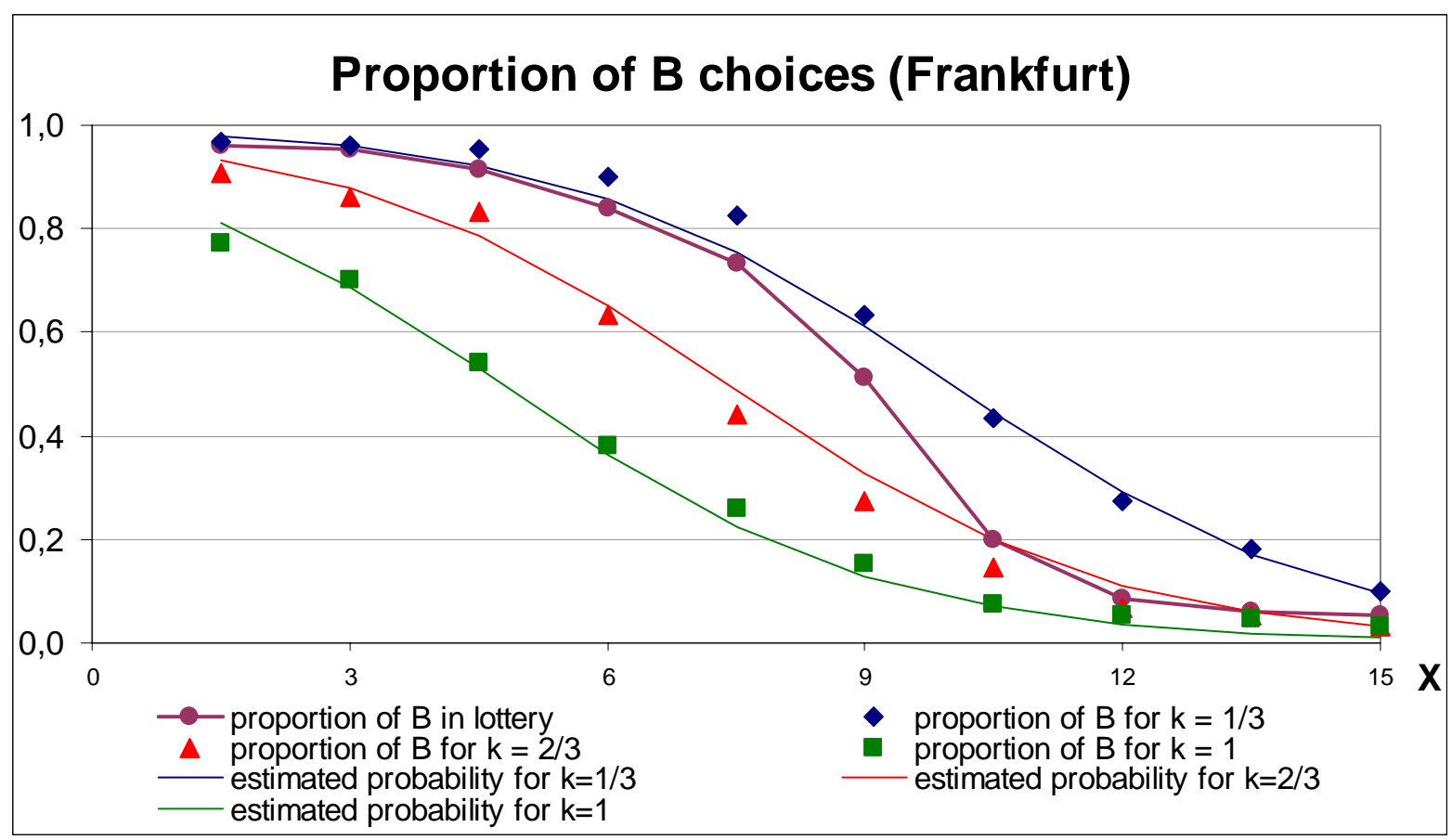

Figure 2. Data from 131 subjects in Frankfurt who played threshold strategies.

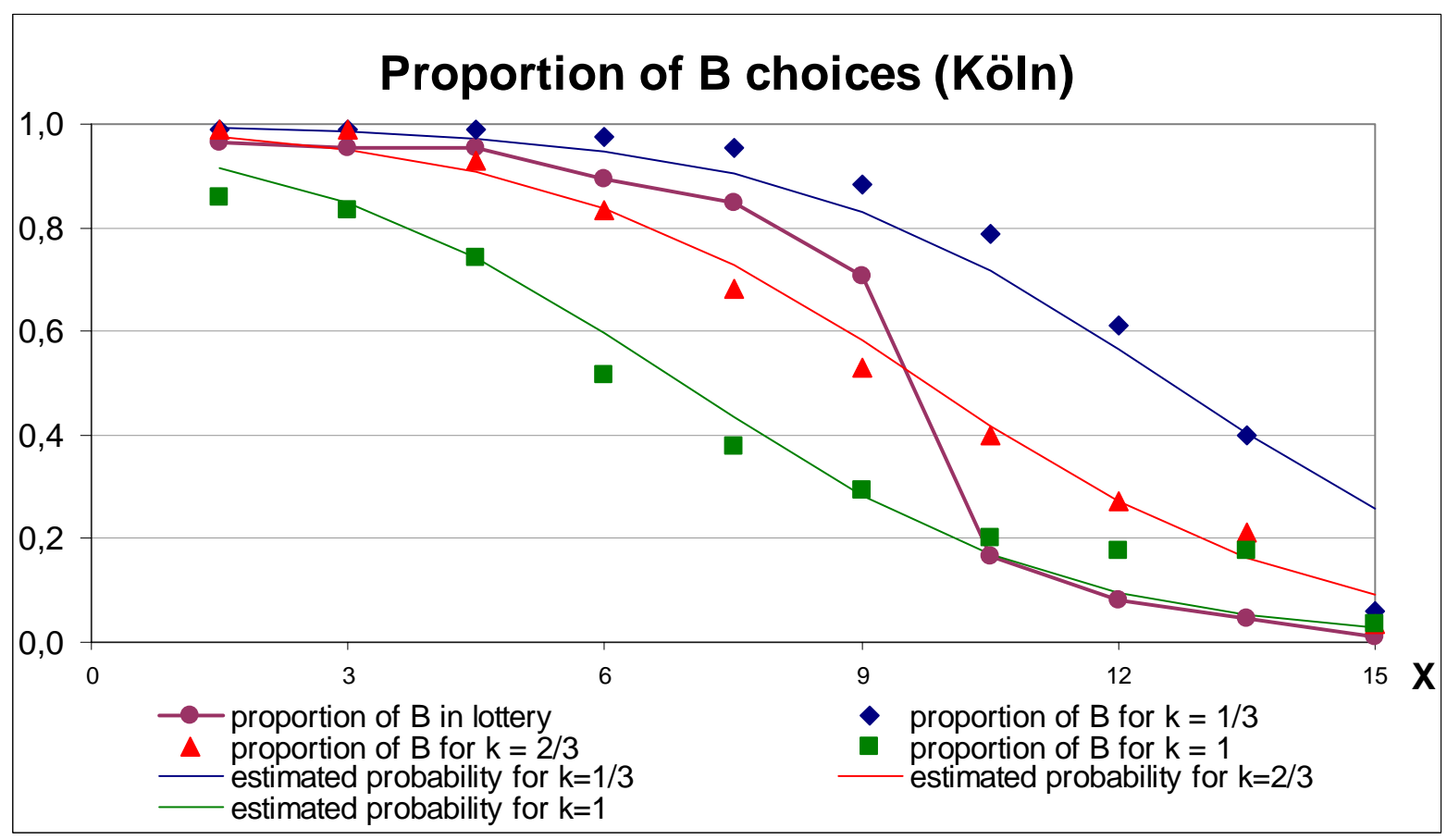

Figure 3. Data from 85 subjects in Köln who played threshold strategies.

In the lottery setup, the proportion of B choices sharply declines between $X=9.00$ and $X=10.50$. Recall that the expected payoff of the lottery is $€ 10.00$. In Frankfurt, 31 per cent 
of participants are approximately risk neutral. 49 per cent prefer 9 Euro to the lottery, which reveals a non-negligible risk aversion. 20 per cent appear to be risk lovers. In Köln 29 per cent are risk averse, 16 per cent risk loving and 55 per sent switch at the expected value. In Barcelona 37 per cent are risk averse and 48 per cent are risk loving.

The distributions of thresholds for coordination games are flatter than for the lottery. Uncertainty about the probability of getting a reward for B adds to individual differences in the evaluation of this uncertainty, i.e. risk aversion. The difference in slopes of distribution functions is most pronounced in the sample from Köln. Stochastic dominance between the four curves in Figure 2 is another expression for the relative order of risk that most subjects associate with the four types of games.

In a coordination game, there are $N$ randomly selected subjects who decide simultaneously between $\mathrm{A}$ and $\mathrm{B}$. If each subject chooses $\mathrm{B}$ with probability $p$, than the probability for getting at least $K$ subjects choosing $\mathrm{B}$ is $1-\operatorname{Bin}(K-1, N, p)$, where $\mathrm{Bin}$ is the cumulative binomial distribution. Replacing $p$ by the observed proportion of B-choices, we derive objective probabilities for successful coordination of randomly drawn subjects. These probabilities are given in Table 6. For these calculations, we use data from all subjects, including nonthreshold players. 
Probabilities for successful coordination

\begin{tabular}{|c|c|c|c|c|c|c|c|c|c|c|c|c|}
\hline$N$ & $K$ & $k$ & $X=1.50$ & 3.00 & 4.50 & 6.00 & 7.50 & 9.00 & 10.50 & 12.00 & 13.50 & 15.00 \\
\hline \multicolumn{13}{|c|}{ Frankfurt } \\
\hline 4 & 2 & $1 / 3$ & 1.00 & 1.00 & 1.00 & 0.99 & 0.98 & 0.86 & 0.59 & 0.29 & 0.16 & 0.06 \\
\hline 7 & 3 & $1 / 3$ & 1.00 & 1.00 & 1.00 & 1.00 & 0.98 & 0.92 & 0.64 & 0.27 & 0.10 & 0.10 \\
\hline 10 & 4 & $1 / 3$ & 1.00 & 1.00 & 1.00 & 1.00 & 1.00 & 0.94 & 0.73 & 0.49 & 0.22 & 0.12 \\
\hline 4 & 3 & $2 / 3$ & 0.92 & 0.92 & 0.88 & 0.66 & 0.27 & 0.06 & 0.01 & 0.01 & 0.00 & 0.00 \\
\hline 7 & 5 & $2 / 3$ & 0.90 & 0.68 & 0.73 & 0.36 & 0.13 & 0.04 & 0.00 & 0.00 & 0.00 & 0.00 \\
\hline 10 & 7 & $2 / 3$ & 0.95 & 0.95 & 0.88 & 0.22 & 0.04 & 0.00 & 0.00 & 0.00 & 0.00 & 0.00 \\
\hline 4 & 4 & 1 & 0.37 & 0.27 & 0.14 & 0.04 & 0.01 & 0.00 & 0.00 & 0.00 & 0.00 & 0.00 \\
\hline 7 & 7 & 1 & 0.09 & 0.04 & 0.01 & 0.00 & 0.00 & 0.00 & 0.00 & 0.00 & 0.00 & 0.00 \\
\hline 10 & 10 & 1 & 0.02 & 0.01 & 0.00 & 0.00 & 0.00 & 0.00 & 0.00 & 0.00 & 0.00 & 0.00 \\
\hline \multicolumn{13}{|c|}{ Barcelona } \\
\hline 7 & 3 & $1 / 3$ & 1.00 & 1.00 & 1.00 & 1.00 & 1.00 & 1.00 & 0.98 & 0.87 & 0.87 & 0.32 \\
\hline 7 & 5 & $2 / 3$ & 0.99 & 0.99 & 0.97 & 0.89 & 0.83 & 0.52 & 0.29 & 0.29 & 0.29 & 0.01 \\
\hline 7 & 7 & 1 & 0.45 & 0.25 & 0.18 & 0.18 & 0.07 & 0.02 & 0.01 & 0.01 & 0.01 & 0.00 \\
\hline \multicolumn{13}{|c|}{ KO } \\
\hline 4 & 2 & $1 / 3$ & 1.00 & 1.00 & 1.00 & 1.00 & 1.00 & 0.98 & 0.97 & 0.83 & 0.45 & 0.01 \\
\hline 7 & 3 & $1 / 3$ & 1.00 & 1.00 & 1.00 & 1.00 & 1.00 & 1.00 & 1.00 & 0.94 & 0.83 & 0.07 \\
\hline 10 & 4 & $1 / 3$ & 1.00 & 1.00 & 1.00 & 1.00 & 1.00 & 1.00 & 0.99 & 0.92 & 0.35 & 0.00 \\
\hline 4 & 3 & $2 / 3$ & 0.99 & 0.99 & 0.94 & 0.85 & 0.55 & 0.17 & 0.13 & 0.07 & 0.02 & 0.00 \\
\hline 7 & 5 & $2 / 3$ & 1.00 & 1.00 & 0.99 & 0.89 & 0.68 & 0.52 & 0.23 & 0.13 & 0.09 & 0.00 \\
\hline 10 & 7 & $2 / 3$ & 1.00 & 1.00 & 1.00 & 0.97 & 0.65 & 0.30 & 0.03 & 0.00 & 0.00 & 0.00 \\
\hline 4 & 4 & 1 & 0.38 & 0.38 & 0.26 & 0.03 & 0.01 & 0.00 & 0.00 & 0.00 & 0.00 & 0.00 \\
\hline 7 & 7 & 1 & 0.45 & 0.34 & 0.13 & 0.03 & 0.00 & 0.00 & 0.00 & 0.00 & 0.00 & 0.00 \\
\hline 10 & 10 & 1 & 0.24 & 0.16 & 0.04 & 0.00 & 0.00 & 0.00 & 0.00 & 0.00 & 0.00 & 0.00 \\
\hline
\end{tabular}

Table 6. Probability for getting at least $K$ B-choices from $N$ subjects, who are randomly selected from the respective subject pools (including non-threshold players).

While the proportion of B-choices is almost independent from the group size, probabilities for successful coordination depend on $N$. However, the major influence comes from the hurdle $k$. It is stunning that for most games success or failure can be predicted (in sample) with an error of less than five per cent although all games with $X<15$ have two equilibria. Even across different subject pools, 43 per cent of all games are predictable with an error rate below 0.05 . So, even if we do not know the subject pool from which players are drawn, we can predict the outcome in half of all coordination games. 
Coordination games with $k=1 / 3$ are successful with a probability of at least 0.95 , whenever the alternative safe payoff is 7.50 or lower. Games that require coordination of all group members are successful with a probability of at most 0.07 , when the alternative safe payoff is 7.50 or higher. These results give an impression of some circumstances under which one may expect coordination or coordination failure. For some games, however, the subject pool has extreme effects on the probability of successful coordination. Consider, for example, the game with $N=7, k=2 / 3$ and $X=7.50$. In Frankfurt, the probability for successful coordination is only 0.13, while it is 0.83 in Barcelona, and 0.68 in Köln.

With an estimated probability $\hat{p}$ of a randomly selected subject choosing $\mathrm{B}$, the estimated probability of successful coordination is given by

$$
\operatorname{prob}(\text { success })=1-\operatorname{Bin}(K-1, N, \hat{p}) \text {. }
$$

Comparing estimated success probabilities with those from randomly drawn subjects, we find that in 60 per cent of all games, the estimates from Frankfurt deviate by less than 5 per cent from objective probabilities of success in Köln. To be more precise, in 21 out of 30 situations, in which success probabilities in Köln are above 0.95, estimates from Frankfurt data predict a success probability above 0.95 . Also, in 33 out of 39 cases, where Frankfurt data predict a success probability below 0.05 , the objective probability in Köln is below 0.05. But, whenever estimated success probabilities are between 0.05 and 0.95 , they deviate from objective probabilities in Köln by more than 5 per cent. Similar results are obtained, when estimates from Köln are compared to data in Frankfurt.

We conclude that observations of behavior in coordination games are useful to detect the extreme cases, in which successful coordination is very likely or very unlikely. But, they do not give reliable estimates of success probabilities for intermediate cases. These are extremely important to know, if an agent participates in a coordination game and thinks about the right switching point. This raises the question, how a player should behave who happens to participate in a coordination game.

\section{Best response strategies}

In this section we analyze which strategy can be recommended to a player of a coordination game. While collective advice would recommend the efficient equilibrium, there is almost no chance to achieve this in situations with a high hurdle or low gains from coordination. We evaluate different refinement concepts for the expected utility that these concepts induce to a single player who interacts with randomly chosen group members.

For a participant, opting for B pays off, if at least $K-1$ other group members decide for B. Thus, from a player's point of view, the probability to be successful with opting for B at an alternative safe payoff $X$ is given by $1-\operatorname{Bin}(K-2, N-1, p)$, where $p$ is again the probability that a randomly selected subject chooses $\mathrm{B}$ in this situation. The best response of a player is to choose $\mathrm{B}$ if and only if

$$
(1-\operatorname{Bin}(K-2, N-1, p)) U(15)>U(X),
$$


where $U$ is the player's utility function. In Table 8 , we compare the recommended numbers of B-choices with two theoretical concepts: the global-game solution and the risk-dominant equilibrium. We give the results for three different utility functions with (i) risk neutrality, (ii) constant absolute risk aversion (CARA), and (iii) constant relative risk aversion (CRRA).

The CARA utility function is given by

$$
U(x)=\frac{1-\exp (-\alpha x)}{\alpha},
$$

where $a$ is the Arrow-Pratt measure of absolute risk aversion. The CRRA utility function is

$$
U(x)=\frac{x^{1-r}}{1-r}
$$

with relative risk aversion $r$. In the calculations, $x$ is replaced by payoffs from the respective situation. Applied parameter values $\alpha=0.092$ and $r=0.415$ are such that a player with any of these utility functions is indifferent between the lottery and a safe payoff of $€ 7.50$.

The global-game solution is the best response of a player who believes that the proportion of other players who choose B has a uniform distribution in [0,1]. Such a player should switch from $\mathrm{B}$ to $\mathrm{A}$ at a threshold $Z^{*}$, given by the solution to

$$
\left(1-\frac{K-1}{N}\right) U(15)=U\left(Z^{*}\right) \text {. }
$$

The risk-dominant equilibrium is the best response to a bi-centric prior. The associated threshold $Z^{*}$ is given by the solution to

$$
\left(1-\operatorname{Bin}\left(K-2, N-1,1-U\left(Z^{*}\right) / U(15)\right)\right) U(15)=U\left(Z^{*}\right) .
$$

The risk-dominant equilibrium is always close to the global-game solution. Parameters of the experiment have been chosen to yield a notable difference between the two equilibium refinements.

From Table 8 one can see that the global-game solution gives a good recommendation for behavior of a risk neutral player in Frankfurt. In Barcelona and Köln, a risk neutral player should choose a higher threshold, but the global-game solution is still a good guide. Risk aversion lowers the optimal number of B-choices. However, with increasing risk aversion the optimal number of B-choices falls less than predicted by global-game solution or risk dominance. In Frankfurt, a risk-averse player can achieve a higher expected payoff by choosing a threshold that is in between the global-game solution calculated for risk-neutrality and the global-game solution based on the player's own utility function. In Barcelona and Köln, even a risk-averse player should choose a higher threshold than predicted by the globalgame solution based on risk neutrality. ${ }^{7}$

\footnotetext{
${ }^{7}$ This in line with previous observations by Heinemann, Nagel and Ockenfels (2003) and Cabrales, Nagel and Armenter (2003), who detect systematic deviations of behavior from the global-game solution towards the payoff-dominant equilibrium.
} 


\section{Optimal and theoretical number of B-choices}

\begin{tabular}{|c|c|c|c|c|c|c|c|c|c|}
\hline & \multicolumn{3}{|c|}{$k=1 / 3$} & \multicolumn{3}{|c|}{$k=2 / 3$} & \multicolumn{3}{|c|}{$k=1$} \\
\hline & $N=4$ & $N=7$ & $N=10$ & $N=4$ & $N=7$ & $N=10$ & $N=4$ & $N=7$ & $N=10$ \\
\hline \multicolumn{10}{|c|}{ (i) Best response of a risk neutral player } \\
\hline in Frankfurt & 7 & 7 & 7 & 4 & 4 & 3 & 2 & 1 & 0 \\
\hline in Barcelona & & 9 & & & 6 & & & 2 & \\
\hline in Köln & 8 & 9 & 8 & 5 & 6 & 5 & 3 & 2 & 1 \\
\hline \multicolumn{10}{|c|}{ Equlibrium refinements assuming risk neutrality } \\
\hline Global-game solution & 7 & 7 & $6-7$ & $4-5$ & 4 & $3-4$ & 2 & 1 & $0-1$ \\
\hline Risk-dominant equilibrium & 6 & 6 & 6 & $4-5$ & 4 & 4 & 3 & 2 & 1 \\
\hline \multicolumn{10}{|c|}{ (ii) Best response of a player with CARA, $\alpha=0.092$} \\
\hline in Frankfurt & 6 & 6 & 7 & 4 & 3 & 3 & 2 & 0 & 0 \\
\hline in Barcelona & & 8 & & & 5 & & & 1 & \\
\hline in Köln & 8 & 8 & 8 & 5 & 5 & 5 & 2 & 2 & 1 \\
\hline
\end{tabular}

Equlibrium refinements assuming CARA, $\alpha=0.092$

$\begin{array}{llllllllll}\text { Global-game solution } & 5 & 5 & 5 & 3 & 2 & 2 & 1 & 0 & 0 \\ \text { Risk-dominant equilibrium } & 5 & 4 & 4 & 3 & 2 & 2 & 1 & 1 & 1\end{array}$

(iii) Best response of a player with CRRA, $r=0.415$

$\begin{array}{llllllllll}\text { in Frankfurt } & 7 & 6 & 7 & 4 & 3 & 3 & 1 & 0 & 0 \\ \text { in Barcelona } & 8 & & & 5 & & & & 1 & \end{array}$

$\begin{array}{llllllllll}\text { in Köln } & 8 & 8 & 8 & 5 & 5 & 5 & 2 & 2 & 1\end{array}$

Equlibrium refinements assuming CRRA, $r=0.415$

\begin{tabular}{|c|c|c|c|c|c|c|c|c|}
\hline Global-game solution & 6 & 5 & 5 & 3 & 2 & 2 & 0 & 0 \\
\hline Risk-dominant equilibrium & 5 & 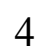 & & 3 & 2 & 2 & 1 & 0 \\
\hline
\end{tabular}

Table 8.

If a risk averse subject in Köln would have known the data from Frankfurt, she would have been better off following the predictions derived from Frankfurt data than following the global game solution. The reverse is not true: the best response in Frankfurt is closer to the global-game solution than to the best response in Köln. Whether risk aversion is described by CARA or CRRA has no big effects, neither on best responses nor on equilibrium refinements. This is also true, when results are calculated for the degrees of risk aversion that are associated with other thresholds in the lottery setup. Comparing recommendations with actual 
behavior (see Table 3), it is obvious that in all three locations most subjects choose B too often in games that require coordination of all subjects $(k=1)$.

When participating in a coordination game, players usually do not know success probabilities and, therefore, cannot predict best responses. Next, we analyze, which general strategy we can recommend to an arbitrary participant in a coordination game. We consider the following strategies:

$\operatorname{GGS}(\alpha) \quad$ global-game solution: choose B if

$$
\left(1-\frac{K-1}{N}\right) U_{\alpha}(15)>U_{\alpha}(Z)
$$

and $\mathrm{A}$ if the reverse inequality holds. Choose $\mathrm{B}$ with probability $1 / 2$ if both sides are equal,

$\operatorname{RDE}(\alpha) \quad$ risk-dominant equilibrium: choose $\mathrm{B}$ if

$$
\left(1-\operatorname{Bin}\left(K-2, N-1,1-U_{\alpha}(Z) / U_{\alpha}(15)\right)\right) U_{\alpha}(15)>U_{\alpha}(Z),
$$

and $\mathrm{A}$ if the reverse inequality holds. Choose $\mathrm{B}$ with probability $1 / 2$ if both sides are equal.

$\mathrm{P} 2 / 3(\alpha) \quad$ best response to other players choosing B with probability $2 / 3$ : choose B if $(1-\operatorname{Bin}(K-2, N-1,2 / 3)) U_{\alpha}(15)>U_{\alpha}(Z)$,

and $\mathrm{A}$ if the reverse inequality holds. Choose $\mathrm{B}$ with probability $1 / 2$ if both sides are equal. We include this strategy, because it gives the best prediction in the experiment studied by Heinemann, Nagel and Ockenfels (2004).

$\operatorname{LLE}(\alpha) \quad$ limiting logit equilibrium, introduced by McKelvey and Palfrey (1995): for any non-negative $\lambda$, a quantal response equilibrium desribes the probability that a player chooses B by the solution to

$$
p(\lambda)=\frac{1}{1+\exp \left(\lambda\left[U_{\alpha}(Z)-\left(1-\operatorname{Bin}(K-2, N-1, p(\lambda)) U_{\alpha}(15)\right]\right)\right.} .
$$

The limit of the continuous path of the solution correspondence $p(\lambda)$ for $\lambda \rightarrow \infty$ defines the limiting logit equilibrium. The associated threshold $Z^{*}$ is given by

$(1-\operatorname{Bin}(K-2, N-1,1 / 2)) U_{\alpha}(15)=U_{\alpha}\left(Z^{*}\right)$.

It amounts to the best response of a player who beliefs that others choose B with probability $1 / 2$.

$\alpha$ is the absolute risk aversion. We distinguish strategies based on a subject's own risk aversion, $\alpha=\alpha^{i}$, and strategies based on $\alpha=0$, for which $U(x)=x$. Strategies based on risk neutrality are easier to calculate and do not require to know one's own risk aversion. However, neglecting risk aversion may lead to losses in expected utility.

The left columns in Table 9 compare, how many subjects could have improved their expected utility (given the absolute risk aversion $\alpha^{i}$, associated with a threshold that is in the middle 
between the highest safe payment, at which the subject chooses the lottery and the lowest safe payment that is preferred to the lottery) by choosing any of the above strategies in comparison to their actual choices. For these comparisons we consider only subjects who played threshold strategies and did not choose the lottery, when the alternative safe payoff was 15 . Success probabilities are calculated from actual choices of the respective subject pool. A vast majority of subjects could have improved their expected utility by any of the considered refinement strategies.

For the right three columns in Table 9 we compare expected utilities from GGS $(0)$ with expected utilities from other strategies. For most subjects in Frankfurt and Köln, GGS(0) leads to a higher expected payoff than any other strategy in pair-wise comparisons. In Barcelona, however, a majority of subjects would achieve higher expected payoffs by using $\mathrm{P} 2 / 3(0)$ or $\mathrm{P} 2 / 3\left(\alpha^{i}\right)$.

\section{Comparison of expected utilities from different strategies}

\begin{tabular}{|c|c|c|c|c|c|c|}
\hline & \multicolumn{3}{|c|}{$\begin{array}{l}\text { Percentage of subjects who would } \\
\text { have achieved higher expected utility } \\
\text { by using the refinement strategy } \\
\text { instead of their actual choices }\end{array}$} & \multicolumn{3}{|c|}{$\begin{array}{l}\text { Percentage of subjects for whom } \\
\text { GGS }(0) \text { leads to a higher expected } \\
\text { utility than the respective other } \\
\text { refinement strategy }\end{array}$} \\
\hline & Frankfurt & Barcelona & Köln & Frankfurt & Barcelona & Köln \\
\hline $\operatorname{GGS}(0)$ & $78 \%$ & $65 \%$ & $88 \%$ & & & \\
\hline $\mathrm{RDE}(0)$ & $77 \%$ & $65 \%$ & $85 \%$ & $100 \%$ & $100 \%$ & $74 \%$ \\
\hline $\mathrm{P} 2 / 3(0)$ & $66 \%$ & $65 \%$ & $81 \%$ & $99 \%$ & $43 \%$ & $74 \%$ \\
\hline $\operatorname{LLE}(0)$ & $75 \%$ & $65 \%$ & $81 \%$ & $94 \%$ & $85 \%$ & $95 \%$ \\
\hline $\operatorname{GGS}\left(\alpha^{i}\right)$ & $77 \%$ & $70 \%$ & $86 \%$ & $65 \%$ & $61 \%$ & $81 \%$ \\
\hline $\operatorname{RDE}\left(\alpha^{i}\right)$ & $77 \%$ & $65 \%$ & $85 \%$ & $94 \%$ & $61 \%$ & $71 \%$ \\
\hline $\mathrm{P} 2 / 3\left(\alpha^{i}\right)$ & $77 \%$ & $70 \%$ & $81 \%$ & $91 \%$ & $43 \%$ & $65 \%$ \\
\hline $\operatorname{LLE}\left(\alpha^{i}\right)$ & $73 \%$ & $70 \%$ & $81 \%$ & $94 \%$ & $63 \%$ & $89 \%$ \\
\hline $\begin{array}{l}\text { Number of } \\
\text { subjects }\end{array}$ & 124 & 23 & 84 & 124 & 23 & 84 \\
\hline
\end{tabular}

Table 9.

It is a striking and surprising result that $\mathrm{GGS}(0)$ does so well in all of these comparisons, although the aggregate behavior differs so much between subject pools. Results do not change much, if we replace $\alpha^{i}$ by minimal or maximal risk aversion consistent with subjects' choices. For most subjects in Frankfurt and Köln, GGS(0) is also the best strategy when 
compared to all others simultaneously. The threshold associated with GGS(0) is simply given by

$$
Z^{*}=15 \cdot\left(1-\frac{K-1}{N}\right)
$$

This strategy is easy to calculate and does not even require knowing one's own risk aversion.

When payoffs are scaled up, one should expect thresholds to fall, because Holt and Laury (2002) show that risk aversion rises with higher payoffs. Given our results on the close relationship between risk aversion and thresholds in coordination games, we expect that highscale payoffs also reduce certainty equivalents for strategic games. This effect shows up in data from two high-stake coordination games in Heinemann, Nagel and Ockenfels (2004). In consequence, we expect that strategies that account for risk aversion may be better than GGS(0) in games with higher payoffs than in our experiment.

\section{Subjective Probabilities}

To find precise measures of individual attitudes towards strategic uncertainty, we estimate subjective beliefs by comparing choices in coordination games with those in the lottery setup. For example, consider a subject who chooses the lottery (B), when the payoff for A is smaller or equal than 6 Euro, but chooses $\mathrm{B}$ in a coordination setup, when the safe alternative is smaller or equal to 9 Euro. This subject seems to believe that successful coordination in situations where A pays 7.50 or 9 Euro has a higher probability than $2 / 3$. If this person expects others to follow threshold strategies (in the questionnaire $83.6 \%$ of all subjects answered yes to the question, whether they expected other subjects to play threshold strategies), she should attribute even higher probabilities to successful coordination on B in situations, where the payoff to $\mathrm{A}$ is smaller than 7.50. On the other hand, if this subject chooses B in a coordination game, only when the payoff to $\mathrm{A}$ is smaller or equal to 4.50 , she reveals that she attributes a probability below $2 / 3$ to a successful coordination on $\mathrm{B}$, whenever the payoff to A is 6 Euro or higher.

More precise measures of subjective beliefs can be obtained by assuming a particular utility function. Here, we use the CARA utility function, but we checked that the CRRA utility function yields about the same results.

Let $X$ be a subject's certainty equivalent of the lottery and $Z$ her threshold in a coordination game. Then,

$$
U(X)=2 / 3 U(15)+1 / 3 U(0) \quad \text { and } \quad U(Z)=q U(15)+(1-q) U(0),
$$

where $q$ is the subjective probability for successful coordination on $\mathrm{B}$, when the alternative safe payoff from $\mathrm{A}$ is $Z$. Assuming CARA, this is equivalent to

$$
\exp (-\alpha X)=1-2 / 3(1-\exp (-15 \alpha)) \quad \text { and } \quad \exp (-\alpha Z)=1-q(1-\exp (-15 \alpha))
$$

The first equation gives us an estimate for $\alpha(X)$ that we use in the second equation to estimate the subjective probability for successful coordination in the situation, where A gives a certain payoff of $Z, q(X, Z)$. 
In our experiment, we measure certainty equivalents up to an interval of 1.50. Consider a subject, who chooses the lottery (B), when the payoff for A is smaller or equal to $X$ Euro, but chooses $\mathrm{B}$ in a coordination setup, when the safe alternative is smaller or equal to $Z$ Euro.

At $Z$, this subject chooses B and prefers the coordination game to the safe payoff $Z$. Thereby, she reveals a subjective probability that is at least $q(X+1.50, Z)$. If this exceeds the objective probability of success in the coordination game with alternative safe payoff of $Z$, then we say that this subject overestimates the probability for successful coordination.

At $Z+1$, the subject chooses $A$ and prefers the safe payoff $Z+1$ over the coordination game. Here, she reveals a subjective probability that is at most $q(X, Z+1.50)$. If this is lower than the objective probability of success in the coordination game with alternative safe payoff of $Z+1.50$, then we say that this subject underestimates the probability for successful coordination.

Subjects, for whom neither of the two conditions above holds, are said to have subjective probabilities that are approximately equal to the objective ones. Table 10 presents these comparisons and shows that most subjects overestimate the probability of success in games with a high coordination requirement, but underestimate success in games with a low hurdle.

Estimated number of subjects, who over- or underestimate the probability of successful coordination

\begin{tabular}{|c|c|c|c|c|c|c|c|c|c|}
\hline \multirow[t]{2}{*}{ Game } & \multicolumn{3}{|c|}{$k=1 / 3$} & \multicolumn{3}{|c|}{$k=2 / 3$} & \multicolumn{3}{|c|}{$k=1$} \\
\hline & $\mathrm{N}=4$ & $\mathrm{~N}=7$ & $\mathrm{~N}=10$ & $\mathrm{~N}=4$ & $\mathrm{~N}=7$ & $\mathrm{~N}=10$ & $\mathrm{~N}=4$ & $\mathrm{~N}=7$ & $\mathrm{~N}=10$ \\
\hline \multirow{2}{*}{$\begin{array}{l}\text { Subjects who } \\
\text { overestimate } \\
\text { success } \\
\text { probability }\end{array}$} & 12 & 6 & 10 & 23 & 19 & 18 & 36 & 26 & 25 \\
\hline & & $23 \%$ & & & $48 \%$ & & & $70 \%$ & \\
\hline \multirow{2}{*}{$\begin{array}{l}\text { Subjective } \\
\text { probability } \\
\text { approximately } \\
\text { equal to } \\
\text { objective }\end{array}$} & 18 & 13 & 6 & $\underbrace{17}$ & 4 & 11 & 7 & 6 & 7 \\
\hline & & $31 \%$ & & & $26 \%$ & & & $16 \%$ & \\
\hline \multirow{2}{*}{$\begin{array}{l}\text { Subjects who } \\
\text { underestimate } \\
\text { success } \\
\text { probability }\end{array}$} & $\underbrace{26}$ & 14 & 16 & 16 & 12 & 5 & 13 & 3 & 2 \\
\hline & & $46 \%$ & & & $26 \%$ & & & $14 \%$ & \\
\hline
\end{tabular}

Table 10.

Most subjects underestimate the probability of successful coordination, when they need only one third of the other players to be successful, while most subjects overestimate the probability of successful coordination in games with $k=2 / 3$ or $k=1$. The proportion of subjects who overestimate probabilities to win in the coordination game tends to rise in $k$ and 
$N$, while the proportion of subjects, who underestimate success probabilities tends to fall in $k$ and $N$.

What are the subjective probabilities associated with the situations at which subjects switch from B to A? To get a precise measure for each subject, we calculate $q(X, Z)$ based on the assumption that the true thresholds $X$ and $Z$ are the highest value of the safe payment, at which a subject chooses B. This overestimates risk aversion, but has no systematic effect on estimated subjective probabilities $q$. Table 11 presents average subjective probabilities for success in the coordination game with hurdle $k$, when the alternative safe payoff is $Z$. Numbers in round brackets are standard deviations, numbers in squared brackets give the number of subjects, who chose this threshold and revealed a finite degree of risk aversion. Again, these estimates do not change substantially, if we apply other utility functions.

\section{Subjective probabilities for successful coordination}

\begin{tabular}{|c|c|c|c|c|c|c|c|c|c|}
\hline \multirow{3}{*}{$\begin{array}{l}\text { Safe payoff } Z \\
0.00\end{array}$} & \multirow{2}{*}{\multicolumn{4}{|c|}{$\begin{array}{c}\text { Estimated } q \text {-values: Mean } \\
k k=1 / 3\end{array}$}} & \multicolumn{5}{|c|}{ (standard deviation) [number of subjects] } \\
\hline & & & & & $k=2 / 3$ & & & $k=1$ & \\
\hline & n.a. & $(-)$ & {$[0]$} & 0 & (0) & [4] & 0 & (0) & [22] \\
\hline 1.50 & 0.67 & $(-)$ & {$[1]$} & 0.40 & $(0.16)$ & {$[6]$} & 0.20 & $(0.14)$ & [9] \\
\hline 3.00 & 0.67 & $(-)$ & {$[1]$} & 0.43 & $(0.17)$ & {$[4]$} & 0.35 & $(0.11)$ & [21] \\
\hline 4.50 & 0.62 & $(0.17)$ & [7] & 0.46 & $(0.14)$ & [25] & 0.45 & $(0.12)$ & [20] \\
\hline 6.00 & 0.61 & $(0.17)$ & [9] & 0.57 & $(0.14)$ & [24] & 0.51 & $(0.08)$ & [15] \\
\hline 7.50 & 0.66 & $(0.12)$ & [25] & 0,60 & $(0.08)$ & [21] & 0.56 & $(0.13)$ & [14] \\
\hline 9.00 & 0.75 & $(0.09)$ & [26] & 0.67 & $(0.07)$ & [17] & 0.71 & $(0.08)$ & [9] \\
\hline 10.50 & 0.76 & $(0.08)$ & [21] & 0.71 & $(0.09)$ & [10] & 0.73 & $(0.05)$ & [3] \\
\hline 12.00 & 0.81 & $(0.06)$ & [12] & 0.91 & $(0.03)$ & [2] & 0.89 & $(-)$ & [1] \\
\hline 13.50 & 0.90 & $(0.09)$ & [11] & 0.80 & $(0.13)$ & {$[3]$} & 0.87 & $(0.07)$ & [2] \\
\hline 15.00 & 1 & $(0)$ & [7] & 1 & $(0)$ & [3] & 1 & $(0)$ & [3] \\
\hline Total* & & & {$[120]$} & & & [119] & & & [119] \\
\hline
\end{tabular}

Table 11. Data from Frankfurt sessions. *These numbers are smaller than the number of subjects who chose threshold strategies, because $q$ can not be calculated, when a subject chooses thresholds of zero or 15 in lottery and coordination game.

At first sight it might surprise that subjective probabilities are increasing in $Z$. It must be emphasized that these are beliefs of different subjects, who actually switched at the respective safe payment. Since $83.6 \%$ of all subjects expected others to follow threshold strategies, subjective probabilities of any single subject should be decreasing in Z. E.g., a subject that switches at 10.50 and has an estimated subjective probability for success of 0.76 in this situation should have higher subjective probabilities for success in situations with lower safe payments and lower subjective probabilities in situations with higher safe payments. 
It is an open question, whether subjective beliefs are formed over the outcome of the order statistic (here: success or failure of coordination on B), or over individual choices. Our experiment provides some answers to this question.

If player $i$ attributes subjective probability $\pi_{i}$ to another randomly selected subject choosing B then her subjective probability for success with action B is $q_{i}=1-\operatorname{Bin}\left(K-2, N-1, \pi_{i}\right)$. This function is invertible, so that we can estimate the subjective probability for another player choosing B by the value $\pi_{i}$ that solves the equation for the estimated $q_{i}$.

For each subject we get estimated subjective probabilities at three different levels of $k$ and $Z$. For a single subject, $\pi_{i}$ and $q_{i}$ should decrease with rising $k$ and $Z$. For more than 70 per cent of subjects, estimated values of $q_{i}$ at the respective threshold are decreasing in $k$, in Frankfurt there were only 3 cases with a reverse order. But, estimated values for $\pi_{i}$ are increasing in $k$ for two third of all subjects. This hints at subjective beliefs being inconsistent with probabilistic beliefs about individual behavior. At the same time, however, subjects reduce their threshold with rising coordination requirement. The lower threshold might compensate the higher hurdle in its effect on beliefs.

Simulations show that subjective beliefs about individual behavior that respond to $k$ and $X$ in the right direction must have variances that do not exceed the variance of the measured distribution of B-choices. The hypothesis that subjects have beliefs about individual actions is consistent with observations only if subject's confidence in their estimates is as high as our confidence in predictions that we can derive from the results of the experiment. It is hard to imagine that subjects have that much trust in the optimality of their decisions. This may be viewed as weak evidence against the hypothesis that subjects form beliefs about individual behavior. The question of how subjective beliefs can be modeled appropriately is analyzed more rigorously in the next section.

\section{Probabilistic Decision Models with Endogenous Beliefs}

Drawing on our previous results, we develop probabilistic decision models to describe behavior. These models include functions describing subjective beliefs. To our knowledge, this is one of the first empirical analyses of probabilistic decision models with endogenous beliefs. ${ }^{8}$ Parameters of the models are estimated by maximizing the likelihood of observed choices.

The reference model (Model 1) treats decisions as a random function that depends on the games' parameters. Model 2 includes personal characteristics, such as risk aversion, gender, age, and the Zuckerman scales as explanatory variables. Including personal characteristics increases the likelihood of observations significantly. ${ }^{9}$ Models 3 and 4 assume that subjects

\footnotetext{
${ }^{8}$ Nyarko and Schotter (2002) estimate subjective beliefs about opponents' behaviour in a repeated game to study changes of beliefs.

${ }^{9}$ While it is common practice in probabilistic decision models to treat all subjects as being identical, McKelvey, Palfrey and Weber (2000) have demonstrated that the data fit can be significantly better, if heterogeneity of agents is considered. They introduce heterogeneity by a distribution of error rates and estimate the parameters of this distribution. Our data allow a more sophisticated treatment of individual differences, because we actually know differences that affect behavior. Besides, we do not see the error rate as a measure of individual error
} 
respond to subjective probabilities that depend on parameters of the game and on personal characteristics. Observed behavior is consistent with probabilistic beliefs about success or failure of coordination. Observations are inconsistent with probabilistic beliefs about other subjects' individual actions.

Model 1 assumes that players respond to the parameters of the payoff function and choose B with a probability that is described by a logistic function,

$$
\operatorname{Prob}(\mathrm{B})=\frac{1}{1+\exp \left(b_{0}-b_{X} X-b_{k} k-b_{N} N\right)} .
$$

Model 2 includes personal characteristics as explanatory variables. Risk aversion is measured by the number B-choices in the lottery setup $B L$. Other explaining variables are gender, age, and the four Zuckerman scales.

$$
\operatorname{Prob}(\mathrm{B})=\frac{1}{1+\exp \left(b_{0}-b_{X} X-b_{k} k-b_{N} N-b_{r} B L-b_{g} \text { gender }-b_{a} a g e-b_{B S} B S-b_{D I S} D I S-b_{E S} E S-b_{T A S} T A S\right)} .
$$

Models 3 and 4 assume that players have probabilistic beliefs about success of coordination. Players respond by maximizing expected utility, but their actual choice is given by a probabilistic choice function that accounts for errors and for individual differences that are not captured in a model's structure. We use the error response function introduced by Luce (1959),

$$
\operatorname{Prob}(\mathrm{B})=\frac{U_{B}^{1 / \mu}}{U_{A}^{1 / \mu}+U_{B}^{1 / \mu}} .
$$

Parameter $\mu$ may be interpreted as an error rate. For $\mu \rightarrow 0$, agents always choose the alternative with the higher expected utility (rational behavior). For $\mu \rightarrow \infty$, agents choose both alternatives with probability $1 / 2$ (random behavior). However, it should be kept in mind that our model (like any econometric model) can just measure average behavior and average beliefs. All individual differences are attributed to random effects that enter models 3 and 4 by the probabilistic choice function for $\mu>0$. In this sense, $\mu$ is rather a measure of diversity than a measure of irrationality.

Utility functions are estimated by observations from the lottery setup. Again, we apply the CARA utility function after checking that CRRA leads to a similar fit of data. For the individual degrees of risk aversion $\alpha^{i}$ we take the values that result from a subject's certainty equivalent being the median between the highest safe payoff at which the subject chooses $\mathrm{B}$ and the lowest safe payoff at which the subject chooses A.

$$
U_{A}=\frac{1-\exp \left(-\alpha^{i} X\right)}{\alpha^{i}}
$$

is the utility from choosing $\mathrm{A}$ in a situation with a safe payoff is $X$, and

probabilities but rather as a compound including unexplained differences between subjects. Allowing different error rates for subjects would blur this measure. Instead, we use known differences, as revealed risk aversion and other personal characteristics to explain differences in individual choices. 


$$
U_{B}=q \frac{1-\exp \left(-\alpha^{i} \cdot 15\right)}{\alpha^{i}}
$$

is the expected utility from choosing B in this situation. In lottery decisions $q=2 / 3$. In coordination games, $q$ is the subjective probability for success. Model 3 assumes that players respond to expectations about success of action $\mathrm{B}$ formed by a logit model. The subjective probability for success of $\mathrm{B}$ is

$$
q=\frac{1}{1+\exp \left(b_{0}-b_{X} X-b_{k} k-b_{N} N-b_{r} B L-b_{g} g e n d e r-b_{a} a g e-b_{B S} B S-b_{D I S} D I S-b_{E S} E S-b_{T A S} T A S\right)} .
$$

Model 4 assumes that players respond to logit expectations about other players' individual choices. The subjective probability for another player choosing B is

$$
p=\frac{1}{1+\exp \left(b_{0}-b_{X} X-b_{k} k-b_{N} N-b_{r} B L-b_{g} g e n d e r-b_{a} a g e-b_{B S} B S-b_{D I S} D I S-b_{E S} E S-b_{T A S} T A S\right)} \text {. }
$$

Here, the resulting subjective probability for success of action $B$ is given by

$$
q=1-\operatorname{Bin}(K-2, N-1, p) .
$$

The likelihood function is constructed to describe the probability of observing actual choices. To compare the estimates, we only use the data from subjects who played threshold strategies, had a finite risk aversion, and completed the questionnaire. Results are displayed in Table 12.

\section{Model Estimates}

\begin{tabular}{lrrrr|rrrr}
\hline & Model 1 & Model 2 & Model 3 & Model 4 & Model 1 & Model 2 & Model 3 & Model 4 \\
\hline$\mu$ & & & 0.51 & 0.53 & & & 0.32 & 0.44 \\
$b_{0}$ & -6.13 & -2.64 & -2.21 & 2.44 & -6.87 & -4.14 & -3.17 & 1.16 \\
$b_{X}$ & -0.48 & -0.58 & -0.30 & -0.20 & -0.44 & -0.48 & -0.08 & -0.16 \\
$b_{k}$ & -3.55 & -4.25 & -3.53 & 2.32 & -3.70 & -4.03 & -3.25 & 2.56 \\
$b_{N}$ & -0.02 & -0.05 & -0.06 & 0.09 & -0.01 & -0.06 & -0.03 & 0.06 \\
$b_{r}$ & & 0.54 & 0.13 & 0.13 & & 0.31 & -0.16 & -0.02 \\
$b_{g}$ & & 0.56 & 0.67 & 0.37 & & 0.28 & 0.62 & 0.49 \\
$b_{a}$ & & 0.04 & 0.04 & 0.04 & & 0.06 & 0.05 & 0.05 \\
$b_{B S}$ & -0.08 & -0.09 & -0.07 & & & & \\
$b_{D I S}$ & & -0.03 & -0.08 & -0.05 & & & & \\
$b_{E S}$ & 0.30 & 0.21 & 0.12 & & & & \\
$b_{T A S}$ & & -0.02 & 0.07 & 0.05 & & & & \\
\hline LL & -1445.9 & -1224.6 & -1341.7 & -1342.0 & -1022.3 & -994.9 & -989.3 & -1006.5 \\
Av.1. & 0.671 & 0.714 & 0.691 & 0.691 & 0.660 & 0.667 & 0.669 & 0.664 \\
\hline Data & 121 subjects in Frankfurt & & & 82 subjects in Köln & \\
\hline
\end{tabular}

Table 12. 
LL is the loglikelihood of observed choices and Av.l. is the average likelihood of a binary choice, calculated by Av.1. $=\exp (\operatorname{LL} /(30 n))$, where $n$ is the number of subjects in the data set. The average likelihood is a measure of predictability of an individual's decision. The reference value is 0.5 for pure random. Model 1 yields an average likelihood of 0.671 in Frankfurt and 0.660 in Köln. A likelihood ratio test reveals that personal characteristics in model 2 increase the likelihood significantly in both locations. For Frankfurt data, this increase is more pronounced than in Köln, where we had no Zuckerman test.

Models 2, 3 and 4 are not nested. Therefore the likelihood ratio cannot serve as a criterion of model selection. However, it is disappointing that modeling beliefs does not increase the average likelihood in comparison to a simple logistic response function. Model 2 clearly delivers the best fit of data in Frankfurt. In Köln, Model 3 does only slightly better.

Whether behavior is consistent with a model can be tested by checking parameter restrictions. Rising safe payoff $X$ and rising hurdle to coordination $k$ should reduce the subjective probability of successful coordination and the subjective probability for another player choosing B. While in Model 3 the coefficients $b_{X}$ and $b_{k}$ are indeed negative, Model 4 predicts that a rising hurdle $k$ increases the subjective probability for another player choosing $\mathrm{B}$, because $b_{k}$ is positive. This result indicates that Model 4 is misspecified and confirms the impression from Section 5 that subjects have subjective probabilities over aggregate outcomes rather than on individual strategies.

Strategic uncertainty might be also be measured by the response precision in a quantal response equilibrium (QRE), introduced by Mc Kelvey and Palfrey (1995). Fitting a single response precision to all situations gives an extremely low likelihood of observations, which raised the idea to estimate response precisions separately for different games. For an observed proportion of $\mathrm{B}$-choices $p$, the response precision in a $\mathrm{QRE}$ is given by

$$
\lambda(X, K, N)=\ln \left(\frac{1-p}{p}\right)\left[U_{\alpha}(X)-\left(1-\operatorname{Bin}(K-2, N-1, p) U_{\alpha}(15)\right]^{-1}\right.
$$

provided that the solution is on the continuous path of the solution correspondence $p(\lambda)$, otherwise it is $\lambda=0$. Response precisions are relatively high in situations, where we could also get reliable forecasts from comparing the outcomes of the experiment at three different places. In situations, for which we cannot predict the outcome, response precisions are low, often zero. A response precision of zero means that the QRE model has no prediction better than random play. This concerns one or two situations in each setup and leads to a poor data fit. The likelihood of observations is lower than for any of the other models.

The frequent occurrence of equilibria with $\lambda=0$ is due to the following property of QRE: $\lambda$ is non-negative if and only if a majority of subjects chooses the action that yields the higher expected utility. In coordination games, the hurdle is often such that a majority may be on the wrong side. For example, if all group members are needed, but only $70 \%$ actually choose B, the likelihood of success is so small that those who choose A have the higher expected utility. Thus, the majority chooses the wrong action and the associated $\lambda$ equals zero. This feature of QRE makes it unsuitable for analyzing coordination games. When $\lambda$ is positive, it provides 
an inverse measure of the variance of individual behavior weighted with the difference between expected payoffs from both actions.

\section{Conclusions}

We have designed an experiment that allows measuring strategic uncertainty and estimating subjective probabilities in coordination games with multiple equilibria. The strategic uncertainty associated with the requirement to coordinate a certain number of group members is measured by the certainty equivalent, i.e. the certain payoff that a subject is willing to give up for the uncertain payoff from coordination. The lower the certainty equivalent of a coordination requirement is, the more risk seems to be associated with it.

The experiment shows that attitudes towards strategic uncertainty are closely related to risk aversion. Certainty equivalents for lotteries and coordination games are positively correlated. This indicates that risk aversion matters in situations of strategic uncertainty. Apparently, subjects treat situations of risk and situations with strategic uncertainty in a similar way, which supports the view that subjective beliefs can be modeled as probabilities. This result should already be valuable for theorists who commonly model subjective beliefs by probability distributions. Estimated subjective probabilities are sensitive to payoffs and to the coordination requirement, while the group size has no significant impact. However, subjective beliefs respond less sensitive to the coordination requirement than objective probabilities.

The outcome of a coordination game with multiple equilibria can be highly predictable, especially when the attitudes of a population towards risk and strategic uncertainty are known. The same knowledge allows recommendations for behavior and will thereby enhance efficiency in the process of achieving coordination. Without precise knowledge of the environment, the global-game solution can be recommended to agents who are engaged in coordination games. Note that this is an advice for a single agent. An advice given to the whole group should always try to move behavior towards the efficient equilibrium.

The quality of predictions can be improved when individual characteristics are taken into account. Subjects who avoid risk or new experiences are less likely to engage in coordination games. But, modeling beliefs does not improve the likelihood of observations compared to a simple logistic response function. The quantal response equilibrium can be used to find separate measures of strategic uncertainty for each decision situation, while certainty equivalents measure subjective beliefs only at the marginal situation at which a subject switches actions. The drawback of quantal response equilibria is that they yield only an aggregate measure depending on the behavior of the whole group, while certainty equivalents measure individual attitudes towards strategic uncertainty.

The design of our experiment opens ways to measure strategic uncertainty in other games as well. A generic approach would ask subjects to decide between safe payoffs of various amounts or lotteries with various success probabilities on one side and participation in a strategic game on the other side. If a subject ever decides for the game, she must also state her decision in the strategic game. Her beliefs about the payoff from the strategic game can then be measured by the marginal payoff or lottery, at which she switches actions. This procedure can actually be applied to a wide variety of games. Analyzing strategic uncertainty helps forecasting behavior and giving advice to players. 


\section{References}

Auman, Robert J. and Jaques H. Dreze (2004) Assessing Strategic Risk, http://ideas.repec.org/p/huj/dispap/dp361.html.

Berninghaus, Siegfried and Karl-Martin Erhart (1998) Time Horizon and Equilibrium Selection in Tacit Coordination Games: Experimental Results, Journal of Economic Behavior and Organization 37, 231-248.

Berninghaus, Siegfried and Karl-Martin Erhart (2001) Coordination and Information: Recent Experimental Evidence, Economic Letters 73, 345-351.

Bohnet, Iris and Richard Zweckhauser (2003) Trust, Risk and Betrayal, http://www.peel.pitt.edu/esa2003/papers/bohnet_trustrisk.pdf.

Cabrales, Antonio, Rosemarie Nagel, and Roc Armenter (2003) Equilibrium Selection through Incomplete Information in Coordination Games: An Experimental Study, discussion paper No. 601, Universitat Pompeu Fabra, Barcelona.

Camerer, Colin, and Risto Karjalainen (1994) Ambiguity-aversion and Non-additive Beliefs in Non-Cooperative Games: Experimental Evidence, in: Bertrand Munier and Mark J. Machina (eds.), Models and Experiments in Risk and Rationality, Kluwer Academic Publishers, 325-358.

Carlsson, Hans and Eric van Damme (1993) Global Games and Equilibrium Selection, Econometrica 61, 989-1018.

Fischbacher, Urs (1999) z-Tree 1.1.0.: Experimenter's Manual, University of Zurich, Institute for Empirical Research in Economics, http://www.iew.unizh.ch/ztree/index.php.

Goree, Jacob K., Charles A. Holt and Thomas R. Palfrey (2002) Risk Averse Behavior in Generalized Matching Pennies Games, http://ideas.repec.org/a/eee/gamebe/v45y2003ilp97113.html.

Harsanyi, John C. and Reinhard Selten (1988), A General Theory of Equilibrium Selection in Games, MIT-Press.

Heinemann, Frank, Rosemarie Nagel and Peter Ockenfels (2004) Global Games on Test: Experimental Analysis of Coordination Games with Public and Private Information, Econometrica 72, 1583-1599.

Heinemann, Frank, Alexander Scivos and Holger Stein (2004) work in progress.

Hellwig, Christian (2002) Imperfect common knowledge of preferences in coordination games, mimeo, UCLA.

Holt, Charles A., and Susan K. Laury (2002) Risk Aversion and Incentive Effects, American Economic Review 92, 1644-1655.

Knight, Frank H. (1921) Risk, Uncertainty and Profit, Houghton Mifflin. 
Kübler, Dorothea and Georg von Weizsäcker (2003) Limited Depth of Reasoning and Failure of Cascade Formation in the Laboratory, Review of Economic Studies 71, 425-441.

Lange, Andreas, John A. List, and Michael K. Price (2004) Auctions with Resale When Private Values Are Uncertain: Theory and Empirical Evidence, NBER paper \#10639.

Luce, Duncan and Howard Raiffa (1957) Games and Decisions, New York: John Wiley \& Sons.

Manski, Charles F. (2004) Measuring Expectations, Econometrica 72, 1329-1376.

Mc Kelvey, Richard D. and Thomas R. Palfrey (1995) Quantal Response Equilibria for Normal Form Games, Games and Economic Behavior 10, 6-38.

Morris, Stephen and Hyun Song Shin (2000) Global Games: Theory and Applications, in: M. Dewatripont, L. Hansen and S. Turnovsky, eds., Advances in Economics and Econometrics, the Eighth World Congress, Cambridge University Press.

Morris, Stephen and Hyun Song Shin (2002) Measuring Strategic Uncertainty, mimeo, London School of Economics and Yale University.

Nyarko, Yaw and Andrew Schotter (2002), An Experimental Study of Belief Learning Using Elicited Beliefs, Econometrica 70, 971-1005.

Schechter, Laura (2004), Traditional Trust measurement and the Risk Confound: An Experiment in Rural Paraguay, http://are.berkeley.edu/ schechte/papers.html.

Schmidt, David, Robert Shupp, James M. Walker, and Elinor Ostrom (2003) Playing Safe in Coordination Games: theRoles of Risk Dominance, Payoff Dominance, and History of Play, Games and Economic Behavior 42, 281-299.

Van Huyck, John B., Raymond C. Battalio and Richard O. Beil (1990) Tacit Coordination Games, Strategic Uncertainty, and Coordination Failure, American Economic Review 80, 234248.

Van Huyck, John B., Raymond C. Battalio and Richard O. Beil (1991) Strategic Uncertainty, Equilibrium Selection, and Coordination Failure in Average Opinion Games, Quarterly Journal of Economics 106, 885-910.

Zuckerman, Marvin (1994) Behavioural expressions and biosocial bases of Sensation Seeking, Cambridge: Cambridge University Press. 


\section{Appendix A1: Instructions}

Instructions for different treatments varied according to group size and order of set-ups. Here, we give the instructions for treatment 7A, which has seven members in each group, starts with lottery choices and ends with coordination games that require unanimity for success with B.

\section{Instructions}

Thank you for participating in this experiment, a project of economic investigation. Your earning depends on your decisions and the decisions of the other participants. From now on until the end of the experiment you are not allowed to communicate with each other. If you have some question raise your the hand and one of the instructors will answer the question in private. Please, do not ask aloud. Thank you very much.

The rules are equal for all the participants.

The experiment consists of 2 stages. The first stage consists of 40 situations. Each situation is independent of the other. In each situation you can decide between A and B. Your payment at the end depends on these decisions.

In the second stage we ask you to fill out a questionnaire.

\section{Stage I}

In this stage two groups are formed of 7 participants in each group. You don't know who will be in your group.

This stage consists of $4 \times 10$ situations, which we explain below. In all situations you have to decide between $\mathrm{A}$ and $\mathrm{B}$. At the end of the first stage 1 out of the 40 situations is chosen randomly. Your payment will be according to the situation picked. Additionally you will get

\section{Euros as a show-up fee.}




\section{Situations of decisions $1-10$ :}

If one of the situations 1-10 is picked at the end, you will be paid according in the following way (have also a look at the table below):

1. If you choose A, you receive a sure payment given in the second column. The payment which is actually chosen depends on the situation chosen randomly.

2. If you choose B, you payment depends on the result of the throw of a die (thrown by the computer).

- If the result of the die is $\mathbf{1}$ or $\mathbf{2}$, you receive 0 Euros.

- If the result of the die is $\mathbf{3 , 4 , 5}$, or $\mathbf{6}$, you receive 15 Euros.

\begin{tabular}{|c|c|c|c|}
\hline Period- & of 1 & & Time remaining[sec]: 237 \\
\hline \multicolumn{4}{|c|}{ Decide between $A$ or $B$ for each of the 10 situations } \\
\hline Number of decision situation & Payment for $\mathrm{A}$ : & Your decision: $\mathrm{A}$ or $\mathrm{B}$ & \multirow{3}{*}{$\begin{array}{l}\text { Payment for } \mathrm{B} \text { : } \\
\text { - Euro, if the result of the die is } 1 \\
\text { or } 2 \\
15 \text { Euros, if the result of the die is } \\
3,4,5, \text { or } 6 \text {. }\end{array}$} \\
\hline 1 & 1.50 Euro & A $C$ C B & \\
\hline 2 & 3.00 Euro & A $\subset \subset B$ & \\
\hline 3 & 4.50 Euro & A $C \subset$ B & dito. \\
\hline 4 & 6.00 Euro & A $C$ C B & dito. \\
\hline 5 & 7.50 Euro & A $C \subset \mathrm{B}$ & dito. \\
\hline 6 & 9.00 Euro & A $C \subset \mathrm{B}$ & dito. \\
\hline 7 & 10.50 Euro & A $C O B$ & dito. \\
\hline 8 & 12.00 Euro & A $\subset \subset B$ & dito. \\
\hline 9 & 13.50 Euro & A $C \subset \mathrm{B}$ & dito. \\
\hline \multirow[t]{2}{*}{10} & 15.00 Euro & A $C \subset \mathrm{B}$ & \multirow[t]{2}{*}{ dito. } \\
\hline & & & \\
\hline \multicolumn{4}{|l|}{ Help } \\
\hline
\end{tabular}

You have to choose between A and B for each situation and you can do it in any order. When you have decided you have to click the button ok. Until you have not pressed the button, you can change your decisions. 
Situations of decisions 11 - 20:

If one of the situations 11-20 is picked at the end, you will be paid according in the following way (have also a look at the table below):

1. If you choose A, you receive a sure payment given in the second column. The payment which is actually chosen depends on the situation chosen randomly.

2. If you choose B, you payment depends on how many members of your group (including yourself) have chosen B:

- If at least 3 out of 7 members of your group have chosen B, you receive 15 Euros.

- If less than 3 members of your group have chosen B you receive 0 Euros.

\begin{tabular}{|c|c|c|c|}
\hline Period & of 1 & & Time remaining[sec]: 93 \\
\hline \multicolumn{4}{|c|}{ Decide between $\mathrm{A}$ or $\mathrm{B}$ for each of the 10 situations. } \\
\hline Number of decision situation & Payment for $\mathrm{A}$ : & Your decision A or $\mathrm{B}$ : & \multirow{2}{*}{$\begin{array}{l}\text { Payment for } \mathrm{B} \text { : } \\
\text { o Euro, if less than } 3 \text { members of } \\
\text { your group choose } \mathrm{B} \text {. }\end{array}$} \\
\hline 11 & 1.50 Euro & $A \subset \subset B$ & \\
\hline 12 & 3.00 Euro & A $C \subset$ B & $\begin{array}{l}15 \text { Euros, if at least } 3 \text { members of } \\
\text { your group choose } B \text {. }\end{array}$ \\
\hline 13 & 4.50 Euro & A $C \subset \mathrm{B}$ & dito. \\
\hline 14 & 6.00 Euro & A $C \subset \mathrm{B}$ & dito. \\
\hline 15 & 7.50 Euro & A $C \subset \mathrm{B}$ & dito. \\
\hline 16 & 9.00 Euro & A $C \subset \mathrm{B}$ & dito. \\
\hline 17 & 10.50 Euro & A $\subset \subset B$ & dito. \\
\hline 18 & 12.00 Euro & A $C$ C B & dito. \\
\hline 19 & 13.50 Euro & A $C \subset \mathrm{B}$ & dito. \\
\hline \multirow[t]{2}{*}{20} & 15.00 Euro & A $C \subset \mathrm{B}$ & \multirow[t]{2}{*}{ dito. } \\
\hline & & & \\
\hline \multicolumn{4}{|l|}{ - Help } \\
\hline \multicolumn{4}{|c|}{ When you have decided please press the button $O K$. } \\
\hline
\end{tabular}

You have to choose between A and B for each situation and you can do it in any order. When you have decided you have to click the button ok. Until you have not pressed the button, you can change your decisions. 


\section{Situations de decisions 21 - 30:}

If one of the situations 21-30 is picked at the end, you will be paid according in the following way (have also a look at the table below):

1. If you choose A, you receive a sure payment given in the second column. The payment which is actually chosen depends on the situation chosen randomly.

2. If you choose B, you payment depends on how many members of your group (including yourself) have chosen B:

- If at least 5 out of 7 members of your group have chosen B, you receive 15 Euros.

- If less than 5 members of your group have chosen B you receive 0 Euros.

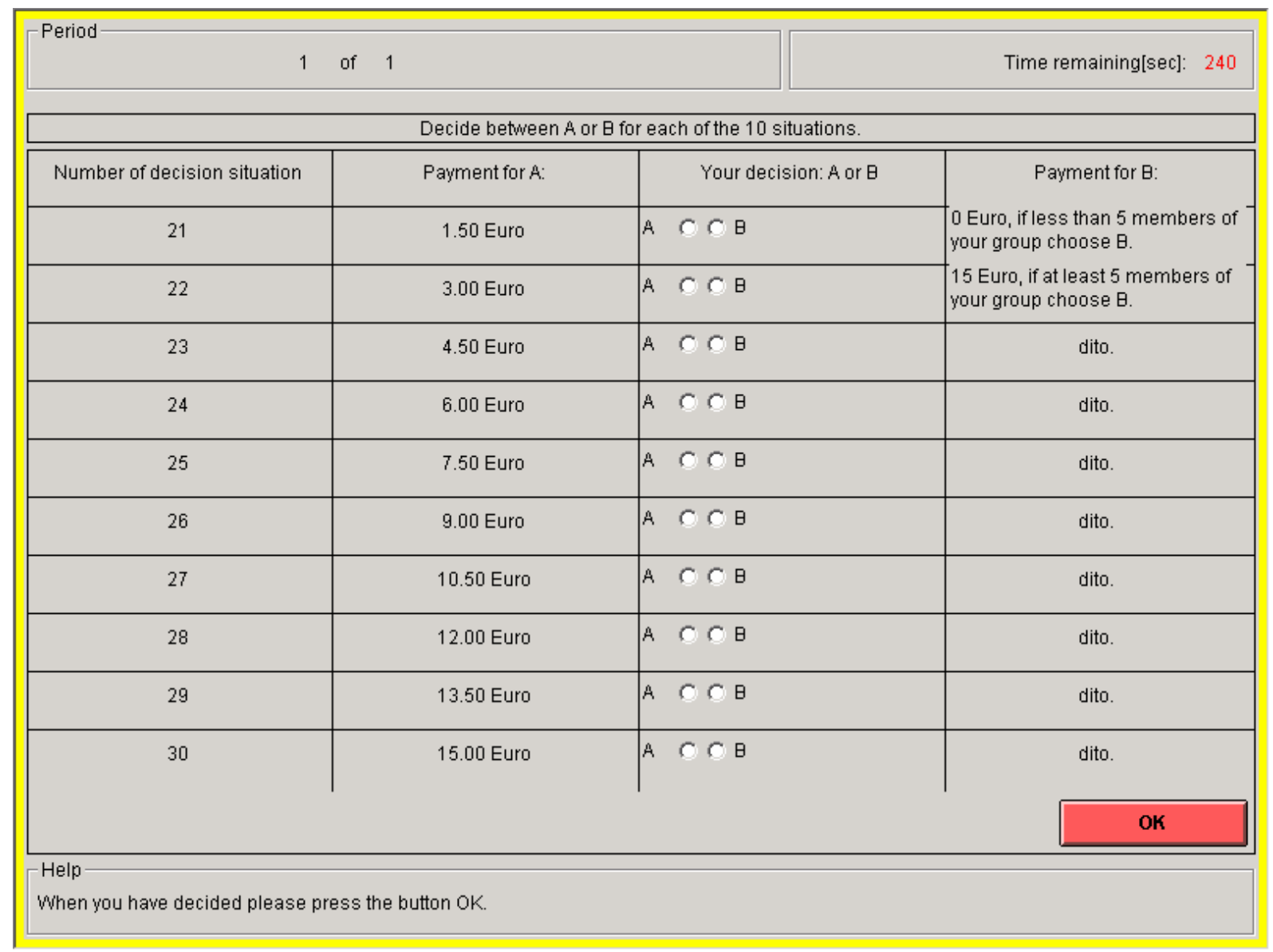

You have to choose between A and B for each situation and you can do it in any order. When you have decided you have to click the button ok. Until you have not pressed the button, you can change your decisions. 


\section{Situations de decisions 31 - 40:}

If one of the situations 21-30 is picked at the end, you will be paid according in the following way (have also a look at the table below):

1. If you choose A, you receive a sure payment given in the second column. The payment which is actually chosen depends on the situation chosen randomly.

2. If you choose B, you payment depends on how many members of your group (including yourself) have chosen B:

- If at least 7 out of 7 members of your group have chosen B, you receive 15 Euros.

- If less than 7 members of your group have chosen B you receive 0 Euros.

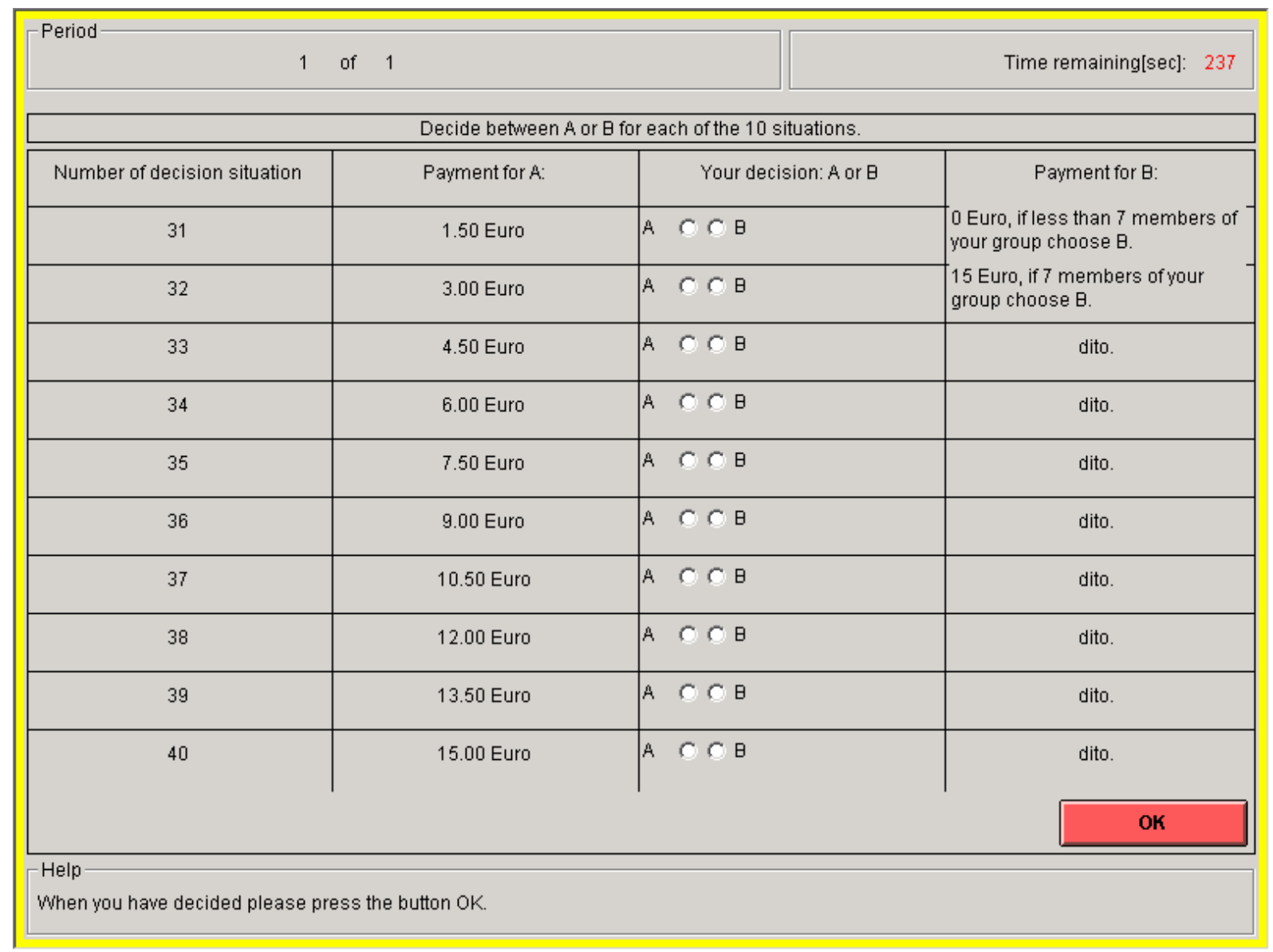

You have to choose between A and B for each situation and you can do it in any order. When you have decided you have to click the button ok. Until you have not pressed the button, you can change your decisions. 
When all participants made all 40 decisions and clicked the last OK-button, the computer randomly selects one of the situations $1-40$. Your payment is determined by the rules of the selected situation.

On the screen you will then be informed about which of the 40 situations has been selected, how many members of your group have decided for A or B, respectively, in this situation, and how much money you will get.

\section{Phase II}

In the secon phase we ask you to fill in a questionnaire. The personal data will be treated confidential and are only used for research. To prove our spendings in case of investigation, we must ask you for your name and address. These data will be stored in separately from the others.

Once you complete the questionnaire, we pay you amount that you earned in phase I including the show-up fee of 5 Euro.

To make sure that everybody understands the rules of the game, we ask you some questions about the game. Phase I will start, when everybody gave the corect answers to these questions.

\section{Appendix A2: Quiz}

Before the experiment started, subjects had to answer a few questions concerning the rules. Here a sample of the quiz for treatment $7 \mathrm{~A}$ which has been discribed by the instructions Appendix A1. This quiz was done with z-tree. Questions $1-5$ were presented one after another. A candidate got the next question only after correctly answering the previous one.

The following questions serve to see if you have understood the instructions. They do not have any influence in decisions or possible payments that follow.

1. How many members does your group have?

How many have to choose $\mathrm{B}$ in situation 17 , so that they receive 15 euros?

In order to receive 15 Euro in situation 37, how many must choose B?

2. In situation 25 you choose A and 4 of the 6 others choose B.

What is your payment?

What is the payment to the other 4 members who chose B?

What would have been your payment if you had chosen B?

3. In situation 39 you choose B and 5 of the other 6 members also choose B.

What is your payment?

What is the payment to the other 5 who chose B?

What would have been your payment if you had chosen A? 
4. In situation 3 you have chosen A, and all the other B.

What is your payment?

What is the payment of the others, if the result of the dice is 5 ?

What is your payment, if you had chosen B and the result of the dice had been 2 ?

5. In situation 16 you have chosen B.

What is your payment, if all the others chose A?

What is your payment, if one of the others chooses B?

What is your payment if 2 of the others choose B?

What is your payment if 3 of the others choose B?

Your answers are correct. The experiment begins when everybody has responded correctly.

\section{Appendix B: Data}

The next table gives the number of B-choices in the four setups by threshold players from sessions in Frankfurt. For non-threshold players we give the sequence of decisions instead. In addition, the table presents each subject's gender and score in the experience seeking (ES) subscale of Zuckerman's SSS-V.

\begin{tabular}{|c|c|c|c|c|c|c|c|}
\hline $\begin{array}{l}\text { Subject } \\
\text { number }\end{array}$ & Session & \#B(Lottery) & $\# \mathrm{~B}(\mathrm{k}=1 / 3)$ & $\# \mathrm{~B}(\mathrm{k}=2 / 3)$ & $\# \mathrm{~B}(\mathrm{k}=1)$ & gender & ES \\
\hline 1 & $4 \mathrm{~A}$ & 7 & 6 & 4 & 2 & $F$ & 3 \\
\hline 2 & & 6 & 6 & 4 & 4 & $M$ & 6 \\
\hline 3 & & 6 & 5 & 4 & 3 & $\mathrm{~F}$ & 6 \\
\hline 4 & & 3 & 6 & 4 & 5 & $M$ & 7 \\
\hline 5 & & 5 & 7 & 6 & 5 & $\mathrm{~F}$ & 5 \\
\hline 6 & & 6 & 7 & 4 & 3 & $\mathrm{M}$ & 6 \\
\hline 7 & & 5 & 7 & 5 & 4 & M & 2 \\
\hline 8 & & 3 & 6 & 3 & 2 & $\mathrm{M}$ & 5 \\
\hline 9 & & 5 & 6 & 5 & 10 & M & 4 \\
\hline 10 & & 5 & 6 & 5 & 4 & $\mathrm{M}$ & 3 \\
\hline 11 & & 6 & 8 & 7 & 7 & M & 5 \\
\hline 12 & & 4 & 5 & 4 & 3 & M & 5 \\
\hline 13 & & 3 & 6 & 10 & 10 & $\mathrm{~F}$ & 6 \\
\hline 14 & & 6 & 9 & 0 & 0 & M & 7 \\
\hline 15 & & 6 & 6 & 4 & 2 & $\mathrm{M}$ & 4 \\
\hline 16 & & 3 & 5 & 4 & 3 & $\mathrm{~F}$ & 5 \\
\hline 17 & & 3 & 5 & 4 & 2 & $\mathrm{~F}$ & 6 \\
\hline 18 & & 6 & 7 & 6 & 5 & $\mathrm{M}$ & 3 \\
\hline 19 & & 6 & 5 & 5 & 4 & M & 6 \\
\hline 20 & & AAABBBAAAA & BВBВBВBвBв & AAAAAAAAAA & AAAAAAAAAA & $\mathrm{M}$ & 9 \\
\hline 21 & $4 \mathrm{~B}$ & 9 & 9 & 9 & 0 & $\mathrm{~F}$ & 6 \\
\hline 22 & & 5 & 6 & 5 & 3 & $\mathrm{M}$ & 6 \\
\hline 23 & & 5 & 7 & 5 & 8 & $\mathrm{~F}$ & 8 \\
\hline 24 & & 5 & 6 & 4 & 3 & $M$ & 4 \\
\hline 25 & & 4 & 4 & 2 & 1 & $\mathrm{M}$ & 3 \\
\hline 26 & & 5 & 3 & 3 & 2 & $\mathrm{~F}$ & 6 \\
\hline 27 & & 6 & 6 & 6 & 5 & $\mathrm{M}$ & 8 \\
\hline 28 & & 7 & 9 & 7 & 7 & $M$ & 6 \\
\hline
\end{tabular}




\begin{tabular}{|c|c|c|c|c|c|c|c|}
\hline 29 & & 5 & 5 & 3 & 0 & $\mathrm{M}$ & 8 \\
\hline 30 & & 5 & 7 & 4 & 3 & $\mathrm{M}$ & 9 \\
\hline 31 & & 4 & 3 & 1 & 1 & $\mathrm{M}$ & 3 \\
\hline 32 & & AABAABBABA & AABAABBAAB & ABAABAABAB & BABAAABABA & $\mathrm{F}$ & 4 \\
\hline 33 & & 2 & 3 & 1 & 0 & $\mathrm{~F}$ & 4 \\
\hline 34 & & 2 & 2 & 3 & 3 & $\mathrm{~F}$ & 1 \\
\hline 35 & & 6 & 9 & 9 & 9 & M & 8 \\
\hline 36 & & 0 & 0 & 0 & 0 & $\mathrm{~F}$ & 6 \\
\hline 37 & $4 \mathrm{C}$ & BBBBBBBBBA & BBBBBBABAA & BBBBBBABBA & BBBBBBBAAA & $\mathrm{M}$ & 2 \\
\hline 38 & & 6 & 5 & 3 & 1 & $\mathrm{M}$ & 8 \\
\hline 39 & & 4 & 5 & 3 & 2 & $\mathrm{~F}$ & 5 \\
\hline 40 & & 7 & 8 & 6 & 5 & $\mathrm{M}$ & 7 \\
\hline 41 & & 5 & 8 & 6 & 4 & $\mathrm{M}$ & 3 \\
\hline 42 & & 5 & 5 & 3 & 2 & $\mathrm{M}$ & 5 \\
\hline 43 & & 6 & 9 & 6 & 4 & $\mathrm{~F}$ & 6 \\
\hline 44 & & BBBBBBAAAB & BBBAAAAAAB & BBBBAAAAAA & ABBBBBAAAA & $\mathrm{F}$ & 7 \\
\hline 45 & & 8 & 7 & 4 & 0 & $\mathrm{~F}$ & 6 \\
\hline 46 & & 6 & 6 & 4 & 3 & $\mathrm{M}$ & 8 \\
\hline 47 & & 5 & 9 & 7 & 6 & $\mathrm{~F}$ & 8 \\
\hline 48 & & 4 & 5 & 4 & 3 & $\mathrm{~F}$ & 5 \\
\hline 49 & $4 \mathrm{D}$ & 10 & 10 & 0 & 0 & $M$ & 5 \\
\hline 50 & & 4 & 9 & 8 & 6 & M & 8 \\
\hline 51 & & 3 & 4 & 0 & 0 & $\mathrm{~F}$ & 8 \\
\hline 52 & & 5 & 5 & 3 & 0 & M & 4 \\
\hline 53 & & 10 & 10 & 10 & 10 & $\mathrm{M}$ & 4 \\
\hline 54 & & 6 & 6 & 5 & 4 & M & 5 \\
\hline 55 & & 5 & 4 & 3 & 0 & $\mathrm{~F}$ & 2 \\
\hline 56 & & 6 & 7 & 5 & 4 & $\mathrm{M}$ & 8 \\
\hline 57 & & 7 & 8 & 5 & 1 & $\mathrm{M}$ & 5 \\
\hline 58 & & 7 & 10 & 6 & 5 & $\mathrm{M}$ & 4 \\
\hline 59 & & BBBAAAAAAA & ABAAAABAAA & ABBBBAAAAA & BBAAAAAAAA & $\mathrm{F}$ & 5 \\
\hline 60 & & 0 & 10 & 0 & 0 & $\mathrm{M}$ & 5 \\
\hline 61 & & 6 & 5 & 5 & 0 & M & 9 \\
\hline 62 & & 6 & 7 & 6 & 5 & $\mathrm{M}$ & 6 \\
\hline 63 & & 10 & 4 & 4 & 4 & $\mathrm{M}$ & 6 \\
\hline 64 & & 7 & 7 & 5 & 4 & M & 2 \\
\hline 65 & $7 \mathrm{~A}$ & 6 & 8 & 6 & 5 & $\mathrm{~F}$ & 9 \\
\hline 66 & & 0 & 0 & 0 & 0 & $\mathrm{~F}$ & 5 \\
\hline 67 & & 0 & 0 & 0 & 0 & $\mathrm{~F}$ & 5 \\
\hline 68 & & 6 & 9 & 5 & 5 & $\mathrm{M}$ & 4 \\
\hline 69 & & 6 & 10 & 6 & 0 & $\mathrm{M}$ & 3 \\
\hline 70 & & 6 & 7 & 6 & 4 & $\mathrm{M}$ & 4 \\
\hline 71 & & 4 & 4 & 2 & 2 & $\mathrm{~F}$ & 6 \\
\hline 72 & & 5 & 6 & 3 & 2 & M & 5 \\
\hline 73 & & 7 & 7 & 7 & 5 & $\mathrm{M}$ & 5 \\
\hline 74 & & 10 & 10 & 0 & 0 & $\mathrm{~F}$ & 3 \\
\hline 75 & & 1 & 1 & 1 & 0 & $\mathrm{~F}$ & 4 \\
\hline 76 & & 5 & 5 & 4 & 3 & $\mathrm{~F}$ & 5 \\
\hline 77 & & 10 & 10 & 3 & 3 & M & 6 \\
\hline 78 & & 8 & 8 & 7 & 5 & $\mathrm{~F}$ & 6 \\
\hline 79 & & 5 & 6 & 5 & 3 & $\mathrm{M}$ & 6 \\
\hline 80 & & ABBABBBABB & BAABBBAAAA & AABBABBBAB & BAABABBBBA & $\mathrm{M}$ & 1 \\
\hline 81 & & 6 & 5 & 5 & 3 & M & 4 \\
\hline 82 & & 5 & 7 & 6 & 5 & $\mathrm{~F}$ & 5 \\
\hline 83 & & 6 & 8 & 6 & 3 & M & 7 \\
\hline 84 & & 5 & 7 & 6 & 6 & $\mathrm{~F}$ & 8 \\
\hline 85 & & 5 & 6 & 5 & 4 & M & 7 \\
\hline 86 & $7 \mathrm{C}$ & BBBABAABAA & BBBAABBBBB & AAAAAAAAAA & AAAAAAAAAA & $\mathrm{F}$ & 8 \\
\hline 87 & & 7 & 4 & 3 & 2 & $\mathrm{~F}$ & 6 \\
\hline 88 & & 6 & 8 & 7 & 7 & M & 6 \\
\hline
\end{tabular}




\begin{tabular}{|c|c|c|c|c|c|c|c|}
\hline 89 & & 6 & 6 & 6 & 6 & $\mathrm{M}$ & 7 \\
\hline 90 & & BBAAABBBAA & AAABBAABAB & BABBAABBAA & BAAABABBAA & $\mathrm{M}$ & 4 \\
\hline 91 & & 6 & 6 & 3 & 2 & $\mathrm{M}$ & 6 \\
\hline 92 & & 2 & 3 & 1 & 0 & $\mathrm{M}$ & 4 \\
\hline 93 & & 6 & 4 & 3 & 2 & $\mathrm{M}$ & 6 \\
\hline 94 & & 7 & 5 & 3 & 1 & $\mathrm{~F}$ & 5 \\
\hline 95 & & 3 & 3 & 0 & 0 & $M$ & 1 \\
\hline 96 & & 7 & 7 & 5 & 4 & M & 7 \\
\hline 97 & & BAABABABAA & AABBAABABA & BABAABBABA & ABABABABBA & $\mathrm{M}$ & 4 \\
\hline 98 & & 4 & 6 & 4 & 0 & $\mathrm{~F}$ & 4 \\
\hline 99 & & 6 & 7 & 4 & 3 & $\mathrm{M}$ & 3 \\
\hline 100 & & 6 & 6 & 6 & 6 & $\mathrm{M}$ & 6 \\
\hline 101 & & 6 & 5 & 4 & 3 & $\mathrm{~F}$ & 5 \\
\hline 102 & & 5 & 7 & 7 & 6 & $M$ & 5 \\
\hline 103 & & 4 & 6 & 1 & 0 & $\mathrm{~F}$ & 4 \\
\hline 104 & & 2 & 4 & 2 & 1 & $\mathrm{~F}$ & 4 \\
\hline 105 & & 5 & 10 & 5 & 4 & $\mathrm{M}$ & 9 \\
\hline 106 & & BВBВBВBВBA & AAAAAAAAAB & AAAAAAAAAB & AAAAAAAAAA & $\mathrm{M}$ & 6 \\
\hline 107 & $10 \mathrm{C}$ & 5 & 5 & 3 & 2 & $\mathrm{M}$ & 9 \\
\hline 108 & & 4 & 6 & 5 & 4 & $\mathrm{~F}$ & 3 \\
\hline 109 & & 2 & 9 & 1 & 1 & $\mathrm{~F}$ & 8 \\
\hline 110 & & 5 & 5 & 4 & 4 & $\mathrm{M}$ & 5 \\
\hline 111 & & 6 & 5 & 0 & 0 & $\mathrm{~F}$ & 6 \\
\hline 112 & & AAAAABBBBB & ВВВBВBВBВB & AAAAAAAAAA & AAAAAAAAAA & $\mathrm{M}$ & 5 \\
\hline 113 & & 7 & 8 & 7 & 6 & $\mathrm{M}$ & 6 \\
\hline 114 & & 4 & 7 & 3 & 2 & $\mathrm{M}$ & 9 \\
\hline 115 & & 6 & 3 & 2 & 1 & $M$ & 4 \\
\hline 116 & & 6 & 5 & 5 & 3 & M & 3 \\
\hline 117 & & 6 & 8 & 7 & 6 & $M$ & 9 \\
\hline 118 & & 6 & 5 & 3 & 0 & M & 4 \\
\hline 119 & & 5 & 9 & 8 & 6 & $\mathrm{M}$ & 7 \\
\hline 120 & & 0 & 0 & 0 & 0 & $\mathrm{M}$ & 3 \\
\hline 121 & & 5 & 6 & 4 & 3 & $\mathrm{M}$ & 7 \\
\hline 122 & & 5 & 5 & 4 & 2 & $M$ & 3 \\
\hline 123 & & 3 & 5 & 3 & 2 & $\mathrm{M}$ & 6 \\
\hline 124 & & 6 & 4 & 3 & 0 & $\mathrm{M}$ & 4 \\
\hline 125 & & ABAAAAAAAA & ABAAAAAAAA & ABAAAAAAAA & ABBBBBBBBB & M & 4 \\
\hline 126 & & 6 & 6 & 3 & 2 & $\mathrm{M}$ & 6 \\
\hline 127 & 10D & 7 & 5 & 3 & 1 & $\mathrm{M}$ & 6 \\
\hline 128 & & 3 & 3 & 3 & 2 & $\mathrm{~F}$ & 3 \\
\hline 129 & & AAAABBBBBB & AAABBBBBBB & ВВВВВВВВВВ & AAABBBBBBB & $\mathrm{M}$ & 5 \\
\hline 130 & & 6 & 8 & 5 & 2 & $M$ & 9 \\
\hline 131 & & 4 & 4 & 3 & 2 & $\mathrm{~F}$ & 4 \\
\hline 132 & & 7 & 10 & 10 & 10 & $M$ & 2 \\
\hline 133 & & 4 & 10 & 3 & 0 & $\mathrm{M}$ & 2 \\
\hline 134 & & ВBВBВBВBAВ & BBBABBAAAB & AAAAAAAAAA & BВBВBВBВАА & $\mathrm{M}$ & 3 \\
\hline 135 & & 6 & 7 & 6 & 5 & $\mathrm{M}$ & 8 \\
\hline 136 & & BABABABABA & AAAAAAAAAA & ВВВВВВВВВВ & AAAAAAAAAA & $\mathrm{F}$ & 6 \\
\hline 137 & & 3 & 6 & 4 & 0 & $\mathrm{~F}$ & 4 \\
\hline 138 & & 4 & 5 & 4 & 2 & $\mathrm{~F}$ & 8 \\
\hline 139 & & 6 & 7 & 5 & 3 & $\mathrm{~F}$ & 7 \\
\hline 140 & & 7 & 8 & 7 & 5 & M & 9 \\
\hline 141 & & 10 & 10 & 0 & 0 & $M$ & 3 \\
\hline 142 & & 8 & 9 & 9 & 9 & $\mathrm{M}$ & 6 \\
\hline 143 & & 5 & 6 & 4 & 3 & $\mathrm{~F}$ & 8 \\
\hline 144 & & 6 & 10 & 10 & 0 & $\mathrm{M}$ & 8 \\
\hline 145 & & 7 & 7 & 3 & 0 & $\mathrm{M}$ & 3 \\
\hline 146 & & 10 & 10 & 5 & 6 & $\mathrm{M}$ & 7 \\
\hline
\end{tabular}


The next table gives the number of B-choices in the four setups by threshold players from sessions in Barcelona. For non-threshold players we give the sequence of decisions instead. In addition, the table presents each subject's gender and score in the experience seeking (ES) subscale of Zuckerman's SSS-V.

\begin{tabular}{|c|c|c|c|c|c|c|c|}
\hline $\begin{array}{l}\text { Subject } \\
\text { number }\end{array}$ & Session & \#B(Lottery) & $\# \mathrm{~B}(\mathrm{k}=1 / 3)$ & $\# \mathrm{~B}(\mathrm{k}=2 / 3)$ & $\# \mathrm{~B}(\mathrm{k}=1)$ & gender & ES \\
\hline 1 & $7 \mathrm{~B}$ & ABBAAAAAAA & BBBBBBBBBB & BBBBBBBBBB & BBBBBBBBBB & $\mathrm{F}$ & 6 \\
\hline 2 & & 9 & 6 & 4 & 5 & $\mathrm{~F}$ & 10 \\
\hline 3 & & 9 & 10 & 10 & 10 & $F$ & 9 \\
\hline 4 & & 7 & 9 & 9 & 7 & $M$ & 10 \\
\hline 5 & & 5 & 7 & 5 & 4 & $M$ & 6 \\
\hline 6 & & 5 & 9 & 9 & 9 & $M$ & 7 \\
\hline 7 & & 5 & 5 & 5 & 5 & $\mathrm{~F}$ & 3 \\
\hline 8 & & 6 & 7 & 6 & 6 & $\mathrm{M}$ & 6 \\
\hline 9 & & 6 & 7 & 5 & 4 & M & 4 \\
\hline 10 & & 5 & 6 & 3 & 1 & $\mathrm{~F}$ & 8 \\
\hline 11 & & 3 & 6 & 5 & 0 & $F$ & 6 \\
\hline 12 & & 6 & 7 & 6 & 5 & M & 6 \\
\hline 13 & & 3 & 0 & 0 & 0 & $\mathrm{~F}$ & 8 \\
\hline 14 & & 4 & 3 & 2 & 1 & M & 5 \\
\hline 1 & 7D & 2 & 9 & 9 & 9 & $\mathrm{M}$ & 5 \\
\hline 2 & & 5 & 4 & 3 & 0 & $\mathrm{M}$ & 9 \\
\hline 3 & & 7 & 10 & 10 & 10 & $\mathrm{~F}$ & 5 \\
\hline 4 & & 10 & 10 & 10 & 10 & $F$ & 7 \\
\hline 5 & & 10 & 10 & 10 & 10 & $\mathrm{~F}$ & 6 \\
\hline 6 & & 10 & 10 & 10 & 10 & $F$ & 5 \\
\hline 7 & & 9 & 9 & 9 & 9 & $\mathrm{~F}$ & 6 \\
\hline 8 & & 10 & 5 & 0 & 4 & $\mathrm{~F}$ & 2 \\
\hline 9 & & 7 & 9 & 9 & 9 & $F$ & 7 \\
\hline 10 & & 9 & 10 & 9 & 9 & $F$ & 7 \\
\hline 11 & & 6 & 9 & 6 & 2 & M & 8 \\
\hline 12 & & 9 & 9 & 9 & 9 & $\mathrm{~F}$ & 3 \\
\hline 13 & & 8 & 10 & 10 & 10 & $\mathrm{~F}$ & 7 \\
\hline 14 & & 5 & 9 & 9 & 9 & $M$ & 7 \\
\hline
\end{tabular}

